\title{
Synthetic biology of minimal systems
}

\section{Petra Schwille \& Stefan Diez}

To cite this article: Petra Schwille \& Stefan Diez (2009) Synthetic biology of minimal systems, Critical Reviews in Biochemistry and Molecular Biology, 44:4, 223-242, DOI: 10.1080/10409230903074549

To link to this article: https://doi.org/10.1080/10409230903074549

\section{曲 Published online: 28 Jul 2009.}

Submit your article to this journal $\llbracket$

Џll Article views: 1132

Q View related articles $ک$

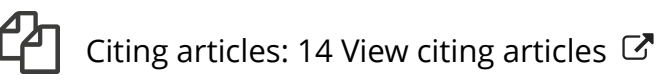




\title{
Synthetic biology of minimal systems
}

\author{
Petra Schwille ${ }^{1,2}$, and Stefan Diez ${ }^{2}$ \\ ${ }^{1}$ Biophysics/BIOTEC, TU Dresden, Dresden, Germany, and ${ }^{2}$ Max Planck Institute of Molecular Cell Biology and \\ Genetics, Dresden, Germany
}

\begin{abstract}
"Synthetic biology" is a concept that has developed together with, or slightly after, "systems biology". But while systems biology aims at the full understanding of large systems by integrating more and more details into their models, synthetic biology phrases different questions, namely: what particular biological function could be obtained with a certain known subsystem of reduced complexity; can this function be manipulated or engineered in artificial environments or genetically modified organisms; and if so, how? The most prominent representation of synthetic biology has so far been microbial engineering by recombinant DNA technology, employing modular concepts known from information technology. However, there are an increasing number of biophysical groups who follow similar strategies of dissecting cellular processes and networks, trying to identify functional minimal modules that could then be combined in a bottom-up approach towards biology. These modules are so far not as particularly defined by their impact on DNA processing, but rather influenced by core fields of biophysics, such as cell mechanics and membrane dynamics. This review will give an overview of some classical and some quite new biophysical strategies for constructing minimal systems of certain cellular modules. We will show that with recent advances in understanding of cytoskeletal and membrane elements, the time might have come to experimentally challenge the concept of a minimal cell.
\end{abstract}

Keywords: In vitro reconstitution; molecular motors; model membranes; artificial cells; microdroplets; biological oscillations

\section{Introduction: synthetic biology from a biophysical perspective}

We have entered the "omics" era of the life sciences, meaning that our general knowledge about biological systems has become vast, complex, and almost impossible to fully comprehend. Consequently, the challenge for quantitative biology and biophysics is to identify appropriate procedures and protocols that allow the researcher to strip down the complexity of a biological system to a level that can still be reliably modeled, but retaining the essential features of its "real" counterpart. The virtue of physics has always been the reductionist approach, which allowed scientists to identify the underlying basic principles of seemingly complex phenomena, and subject them to rigorous mathematical treatment. Biological systems are obviously among the most complex phenomena we can think of, and it is fair to state that our rapidly increasing knowledge does not make it easier to identify a small set of fundamental principles of the big concept of "life" that can be defined and quantitatively understood. Nevertheless, it is our firm conviction that only by strong interdisciplinary exchange, applying intelligent reductionist approaches also to biology, will we be able to meet the intellectual and practical challenges of the 21 st century.

The famous physicist Richard Feynman is credited with the quote "What I cannot create, I do not understand" (Hawking, 2001). In a strict sense, following this quote, we would only fully understand a biological system if we were able to make it from scratch. Besides ethical implications that we will not be able to address here, it appears to be a rather hopeless enterprise to construct a "modern" cell, let alone a whole organism, in all its complexity. On the other hand, life has arisen from presumably much simpler subsystems (Deamer, 2005),

Address for Correspondence: Petra Schwille, Biophysics/BIOTEC, TU Dresden, Tatzberg 47-51, D-01307 Dresden, Germany. Tel: +49 351463 40328. Fax: +49 351463 40342. E-mail: schwille@biotec.tu-dresden.de 
containing unknown and probably no longer existing key molecules. The success of several functional in vitro assays for biological subsystems (discussed below) functioning in environments of dramatically reduced complexity suggests that it is indeed possible to reconstitute essential features and distinct modules of the cell from small and physically controllable sets of molecules, and by doing this to learn more about the fundamental physical and chemical laws on which nature builds the phenomenon of life (Hartwell et al., 1999). This striving for a better understanding of biological, particularly cellular, systems via a so-called "bottom-up biology" is the primary motivation of a new branch of biophysics and biology, which belongs to the larger field of synthetic biology, although it distinguishes itself from most of the more "classical" representations: Engineering biological parts and circuits based on recombinant DNA technology (Ferber, 2004; Benner and Sismour, 2005; Endy, 2005; Arkin, 2008; Canton et al., 2008).

The modern way to look at proteins, DNA and other key molecules that were identified as the main organizing structures in living systems is that of so-called "molecular machines" (Browne and Feringa, 2006). We believe that evolution enabled these molecules to adopt the most intricate and complex shapes and functionalities, which are now perfectly suited to fulfilling specific tasks in their cellular environment. With technological development running into problems of continuous miniaturization, in particular the assembly of ever smaller functional units, it has become a widely shared hope that nanoscale biological machines that have already had their functionality improved over billions of years could be smartly integrated into nanotechnological devices. They can fulfill tasks as structural templates (Aldaye et al., 2008), in the transport of matter (Hess et al., 2001), in ATP production (Choi and Motemagno, 2005), or more generally act as individually addressable molecular switches in higher organized circuits. There are many developments in the field of nanobiotechnology that already support this view. For example, DNA has already shown a remarkable potential in nanoengineering (Winfree et al., 1998; Rothemund, 2006), since this molecule can be relatively easily manipulated, functionalized, and reproduced in large numbers. On the other hand, energy-driven proteins such as molecular motors have found use in transporting non-biological material (Hess and Vogel, 2001), and the combination of proteins and biological structures with inorganic materials have yielded most amazing new tools for the materials sciences (Seeman and Belcher, 2002).

In all these efforts to use biological material in technological processes, the key task is that of proper interfacing, i.e. guaranteeing ideal (or at least, sufficient) environmental conditions to keep the proteins or nucleic acids intact and functional. This is relatively easy for simple molecular functions that just need proper temperature, ion concentration, and $\mathrm{pH}$, but it is much more of a challenge if complex functionality is to be reconstituted, involving the coordination and orchestration of many different biological parts at once. Some biological functions that may be of particular interest and importance for engineering purposes, such as energy production, involve a multitude of molecules and structures that are much harder to assemble part for part in a test tube. In these cases, it is absolutely essential to find out which molecules are of key relevance, and which ones are just supplemental to certain functionality. In other words, the task of identifying the minimal system that fulfils a specific biological function becomes apparent. In this respect, the aims of engineering and bioengineering converge with the interests of physics and biophysics, in identifying the smallest functional unit that still resembles the biological system well enough to mimic its essential features, but can now be quantitatively understood and technically mastered.

The approach of identifying a minimal functional system seems in some aspects contradictory to the aims of biology, which always has the complete living organism in view, and whose genuine interest is to understand the entire system in all its complexity. However, as already pointed out, with all information known to date and with much more to be expected, this task of comprehending the complete picture seems to become impossible, even with all the computational power that is or might be available. Also, systematic gene knockouts have provided evidence that evolution has accumulated a lot of redundancy in living systems, so that probably not all the proteins which can be identified in an organism are in fact relevant to life functions. For this reason, cell and molecular biologists, who have in recent years been successfully designing and using assays to functionally reconstitute biological functions in vitro, are becoming more and more attracted by the idea of creating minimal systems that can be better controlled and analyzed than the complete biological phenomenon.

Synthetic biology has at least two goals: (1) the reengineering or reconstitution of existing systems for better (quantitative) understanding; and, based on this knowledge, (2) the engineering of new systems, or of biological functions that do not (yet) exist in nature. This article will primarily deal with the first aim, discussing the enormous impact of minimal systems on the development of modern biological physics. It is not within the scope of this article to provide a comprehensive overview of the many different ways of constructing controllable subsets of biological systems, e.g. the protein purification and in vitro analysis methods carried out thousands of times in laboratories worldwide every day. Our selection of approaches focuses on minimal systems that form the very core of a cellular system, comprising information 
units such as nucleic acids, membrane compartments to encapsulate them, and machinery to transform, and finally replicate, these compartments using biological energy, such as motor and filament systems.

Since our original motivation to deal with synthetic biology was primarily biophysical, we emphasize those model systems that have in the past been most rewarding in terms of a quantitative description of biological structure formation and self-organization. Part A will give a short overview of the successful reconstitution of molecular motor systems on filaments of the cytoskeleton, a system that has probably benefited most so far from the so-called "single molecule techniques" including single molecule tracking and force measurements. Part B will be devoted to successful model systems of membranes and membrane compartments, with reduced compositional complexity, but retaining essential features such as functional domains, potentially active in specific recruitment of membrane-sculpting or -transforming protein machinery. Part $\mathrm{C}$ is devoted to a discussion of minimal systems that encapsulate biological information or biochemical processes in general, a fundamental requirement for all evolvable life forms. Part D, finally, discusses some of the recent accomplishments in reconstituting the most fascinating ability of living structures, that of dynamic pattern formation under energy consumption, potentially being the physical basis for cell and tissue organization, and generally the development of all higher organisms (Turing, 1952).

\section{Part A: Minimal systems for the understanding of cellular mechanics}

The mechanical stability and integrity of biological cells is provided by the cytoskeleton, a semidilute meshwork of biopolymers. Recent research has underscored its role as a dynamic network, whose passive and active mechanical performance is intimately linked to many biological functions. In vitro reconstitution of "functional modules" of the cytoskeleton, namely cytoskeletal filaments, motor proteins and interactions between them, is now seen as a way of balancing the mutually conflicting demands for simplicity, which is required for systematic and quantitative studies, and for a sufficient degree of complexity that allows a faithful representation of biological functions (Bausch and Kroy, 2006).

\section{Cytokeletal motor systems}

Transport in cell biology is mainly mediated by biomolecular motors, the active workhorses in cells. They are complexes of two or more proteins that convert chemical energy, usually in the form of the high-energy phosphate bond of ATP, into directed motion. These motors include myosins (the most prominent example being muscle myosin-II) moving along actin filaments (diameter $6 \mathrm{~nm}$, repeat length $5.5 \mathrm{~nm}$, composed of two filament strands) as well as members of the kinesin and dynein families. The latter motors move on microtubules (see Figure 1a), which are stiff, hollow cylinders (diameter $25 \mathrm{~nm}$ ) composed of about 13 parallel protofilaments that are made of tubulin dimers (repeat length $8 \mathrm{~nm}$ ). Actin filaments and microtubules, which possess a structural polarity important for the directed movement of motor proteins, form a network of highways within cells, and localized cues are used to target specific cargoes to specific sites (Howard, 2001).

The general setups for studying cytoskeletal motor proteins outside cells - the so-called motility assays are depicted in Figures $1 b-1 d$. In the gliding assay, the motors are immobilized on a surface and the filaments glide over the assembly (Figure $1 \mathrm{~b}$ ). In the stepping
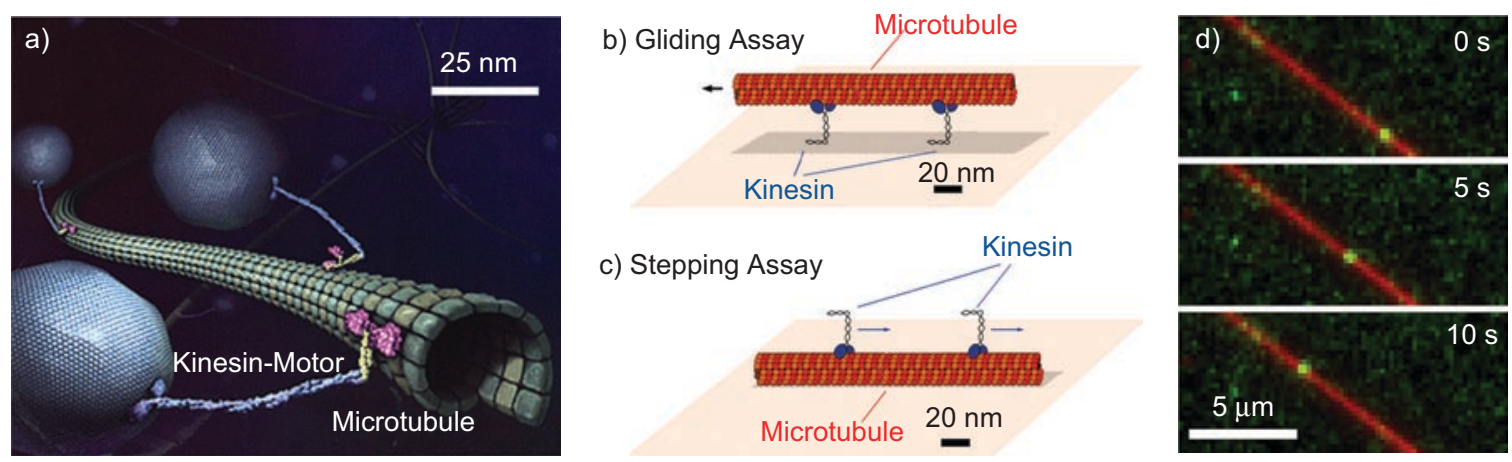

Figure 1. Kinesin-microtubule assays. (a) In a cellular environment, kinesin-1 motors transport cargo, such as membrane-bounded vesicles, along microtubule tracks (Image courtesy of G. Johnson). The motility of molecular motors can be reconstituted in vitro in (b) gliding assays (where the filaments are propelled by surface-bound motor molecules) and (c) stepping assays (where the filaments are immobilized on the surface and motors walk on them). (d) Sequence of fluorescent micrographs showing the movement of a kinesin motor (labeled with the green fluorescent protein) along a microtubule (red) in a single-molecule stepping assay. Images were acquired at the indicated times using totalinternal-reflection fluorescence microscopy. 
assay, the filaments are laid out on the surface where they form tracks for the motors (possibly carrying cellular or artificial cargo) to move along (Figures 1c, 1d). Both assays are performed in aqueous solution, where the environmental conditions are chosen similar to those present in cells (Allen et al., 1982; Vale et al., 1985b). One important early finding from these assays was that nonhydrolyzable analogs of ATP (such as AMPPNP) lead to the stabilization of microtubule-organelle complexes, directly indicating that ATPase activity was responsible for active transport (Lasek and Brady, 1985). Combined with the possibility of efficiently polymerizing and stabilizing microtubules in vitro (Weisenberg, 1972) these results enabled the affinity-purification of motor proteins (later on to be used in reconstituted assays) from cell lysates (Vale et al., 1985a; Paschal et al., 1991).

\section{Single-motor studies}

With regard to observing motor-driven movement under the light microscope, high contrast transmitted-light techniques (Nagashima and Asakura, 1980; Allen et al., 1981; Inoue, 1981) or fluorescence markers (Yanagida et al., 1984; Kron and Spudich, 1986) were applied. By the further development of these techniques, as well as by the careful tuning of the parameters in the motility assays, it became possible to investigate molecular motors at the level of single molecules. As such, it could be shown in gliding assays at low motor density that kinesin- 1 is a processive motor, capable of performing hundreds of steps before dissociating (Howard et al., 1989). To tackle the question if kinesin-1 moves in a stepwise manner along microtubules, stepping assays were performed with individual motors attached to micronsized beads. These beads were held in the focus of a laser trap. Using a sensitive photodetector, Block's group identified quantized 8-nm steps (Svoboda et al., 1993) and single-motor forces of about 5-6 pN (Svoboda and Block, 1994). Similar experiments were carried with myosin motors (Finer et al., 1994). To unravel the question of energy consumption, total-internal reflection fluorescence (TIRF) microscopy was applied by the Yanagida group to image individual fluorescently-labeled myosin subfragments simultaneously with the association of fluorescently-labeled ATP molecules (Funatsu et al., 1995). The movement of individual kinesin-1 motors labeled with Cy3 (Vale et al., 1996) or with the green fluorescent protein (GFP) (Pierce et al., 1997) along microtubules was recorded. Since then, the field of in vitro single molecule research on cytoskeletal motor proteins has vastly expanded and served as a basis for the investigation of other single-molecule interactions, such the interactions of proteins with nucleic acids. Recent advances on the technological side include the application of novel optical markers such as quantum dots (Reck-Peterson et al., 2006) or metal nanoparticles (Dunn and Spudich, 2007), improved blocking techniques to prevent undesired fluorescence from proteins binding to the substrate surface (Helenius et al., 2006; Bieling et al., 2007), sophisticated nanometer tracking algorithms (Thompson et al., 2002; Yildiz et al., 2003), and single-molecule fluorescence resonance energy transfer (FRET) approaches (Ha et al., 1996; Mori et al., 2007).

\section{Multi-motor transport}

In cells, motor proteins usually operate in small groups (Ashkin et al., 1990; Gross et al., 2002). In order to test for cooperative effects between motors of the same directionality, various in vitro experiments with coupled motors have been performed: (i) multiple monomeric kinesin-1 motors attached to artificial protein scaffolds showed enhanced hydrolysis activity and microtubule gliding velocity (Diehl et al., 2006); (ii) beads pulled by an increasing number of dimeric kinesin-1 motors exhibited strongly increased run-lengths (Beeg et al., 2008); and (iii) cargo transported by multiple dimeric kinesin-1 motors moved with fractional steps (Leduc et al., 2007). These fractional steps, observed in our group, indicate a lack of synchronization between the motors. By improving the quality of biocompatible surfaces to immobilize motor proteins at controlled surface densities, it was shown that the stochasticity of stepping can cause mutual interference (Bieling et al., 2008). In particular, mechanically coupled kinesin-1 molecules lacking a number of flexible elements in their non-motor parts moved microtubules with reduced velocity (Bieling et al., 2008; Crevenna et al., 2008). The methods, by which motors are adsorbed to artificial surfaces in motility assays, have also been identified as crucial factors when employing myosin motors (Mansson et al., 2008). Additionally, motility assays using motors with opposite directionality reproduced a variety of transport modes including bidirectional movement (Tao et al., 2006; Vale et al., 1992) as formerly observed in vivo (Schnapp et al., 1985) and predicted in theory (Badoual et al., 2002).

Recent advances in understanding how motor proteins work have raised hopes that they might find novel applications as nanomachines in miniaturized lab-onchip systems (see Figure 2). For example, they could be used to generate and manipulate artificial nanostructures, autonomously measure surface properties or sort molecular reagents. However, for these applications, their movement has to be controllable by external signals. So far, spatio-temporal control over motor-driven filaments has been achieved using topographical and chemical surface modifications (Hiratsuka et al., 2001; van den Heuvel et al., 2005), as well as hydrodynamic (Gast et al., 2006), thermal (Ionov et al., 2006) and electric fields (van den Heuvel et al., 2006). In addition to 


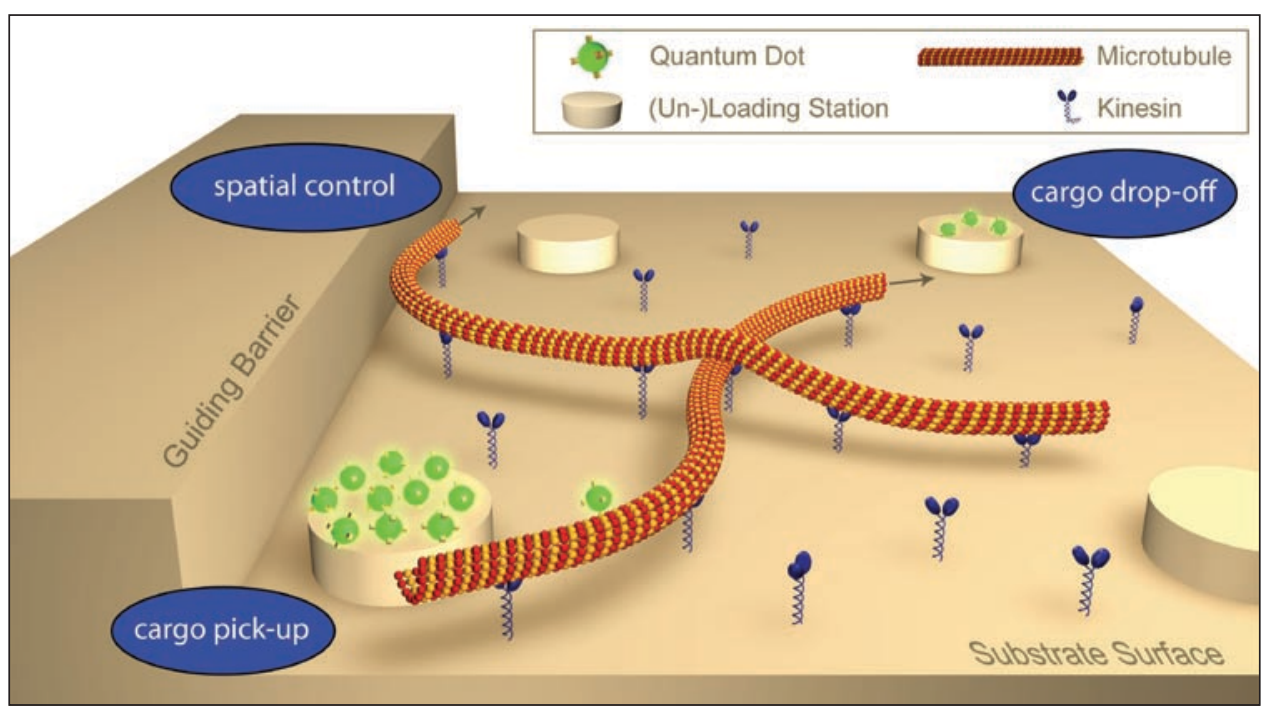

Figure 2. Example of a nanotechnological transport system based on motor proteins in a synthetic environment. Microtubules are propelled over the surface by immobilized kinesin motors in the presence of ATP. Cargo (e. g. quantum dots) can be picked up at a loading station and - by the means of spatial guiding systems - delivered to a drop-off point.

these basic techniques for controlling motion, some first applications have been demonstrated. These include the transport of silicon microchips (Limberis and Stewart, 2000) and virus particles (Bachand et al., 2006), the setup of DNA networks (Dinu et al., 2006), the sorting of molecular assemblies (Ionov et al., 2005; Lin et al., 2008; Raab and Hancock, 2008), and the measurement of forces in the pN range (Hess et al., 2002) (for recent reviews see also Hess, 2006; van den Heuvel and Dekker, 2007; Goel and Vogel, 2008).

\section{Motor-driven structure formation}

Besides directed cargo transport, motor proteins are also involved in the establishment and maintenance of cellular structures, such as the mitotic spindle. For this functionality, microtubule cross-linking motors - which possess a second microtubule interaction site - are of particular interest. To better understand their role, microtubule-microtubule sliding experiments (with one microtubule fixed to the substrate surface and the other one free) were reconstituted in vitro. Using this geometry, it has been shown that kinesin- 5 and kinesin-14 drive the sliding of microtubules depending on their relative orientation (Kapitein et al., 2005, Fink et al., 2009). Moreover, it was demonstrated that kinesin-5 can switch between diffusional and directed movement upon microtubule cross-linking (Kapitein et al., 2008). For nanotechnological applications, it was shown that filament-filament sliding can provide a means for the spatial guiding of cargo-carrying microtubule-shuttles along predefined tracks (Reuther et al., 2006). When purified kinesin-1 (Urrutia et al., 1991) or engineered, multi-headed kinesin-1 constructs (Nedelec et al., 1997) were mixed with stabilized microtubules in solution, dynamic asters and a variety of other large-scale patterns appeared through self-organization. Functional nuclei and mitotic spindles were shown to assemble around DNA-coated beads incubated in Xenopus egg extracts (Heald et al., 1996).

\section{Microtubule dynamics}

While the experimental approaches described so far have made use of stabilized filaments, they are, in reality, highly dynamic structures. For microtubules, this behavior was elegantly demonstrated by Mitchison and Kirschner in a reconstituted system where microtubule extensions were grown off from stabilized seeds (Mitchison and Kirschner, 1984). It was observed that the plus ends of the microtubules switched between phases of slow growth and fast shrinkage, a behavior which was termed "dynamic instability". Besides the fact that dynamic instability provided a mechanism by which microtubules could reassemble into different structures during the cell cycle, it was hypothesized that their growth and shrinkage might also be directly (i.e. without the activity of motor proteins) involved in processes of force generation, e.g. during chromosome movement. In vitro studies with purified tubulin indeed confirmed that microtubules themselves can act as molecular machines. Attaching microtubules to a substrate at one end and causing them to push against a microfabricated rigid barrier with the other (growing) end caused the buckling of the filament (Dogterom and Yurke, 1997). Moreover, it was shown that polymerizing microtubules 
can deform membranes (Fygenson et al., 1997) while depolymerizing microtubules can move beads attached to their end (Coue et al., 1991). The forces generated by a growing microtubule are estimated to be about $4 \mathrm{pN}$ (Dogterom and Yurke, 1997) (comparable to the force of a single motor protein) while much lower forces are generated by growing actin filaments (Footer et al., 2007). In order to reconstitute the outcome of these forces in the closed environment of living cells, dynamic microtubule asters were placed in micro-fabricated chambers (Faivre-Moskalenko and Dogterom, 2002; Holy et al., 1997). In such confined geometries, the pushing forces were capable of centering the aster, similar to the centering of the nucleus in yeast (Tran et al., 2001). In cells, the dynamics of microtubules are further influenced by motor proteins (e.g. mitotic centromere-associated kinesins) and microtubule-associated proteins that bind all along the microtubule lattice or specifically to the end of the microtubules. The contributions of these proteins to the dynamic instability of microtubules have been recently illuminated in reconstituted multicomponent assays (Kinoshita et al., 2001) and single-molecule assays (Helenius et al., 2006; Varga et al., 2006; Bieling et al., 2007; Brouhard et al., 2008).

\section{Actin polymerization}

Actin polymerization is essential for cell locomotion and is thought to generate the force responsible for cellular protrusions. Moreover, bacteria such as Listeria and Shigella use actin assembly to propel themselves in living cells (Theriot et al., 1992). The in vitro reconstitution of this propulsion machinery using purified components (in the absence of myosin motors) has allowed Carlier's group to determine the minimal requirements of actin-based motility (Loisel et al., 1999). This way, it was found that in addition to actin, an activated Arp2/3 complex for enhanced nucleation, actin depolymerizing factors, capping proteins, and ATP were required for sustained motility. Propulsion is then due to actin polymerization at one end of the actin filaments (at the surface of the bacterium) and depolymerization at the other end in a so called "treadmilling" process. Polystyrene beads coated with purified bacterial protein ActA protein were shown to undergo directional movement in an actin-rich cytoplasmic extract. Thus, the actin polymerization-based motility can be used to move nonbiological cargo, as has been demonstrated for classical motor molecules such as kinesin and myosin (Cameron et al., 1999). Quantitative force measurements were performed in a micromanipulation experiment, where a comet growing from a coated polystyrene bead was held by a micropipette while the bead was attached to a force probe (Marcy et al., 2004).

\section{Part B: Minimal systems for cellular membranes}

\section{Supported or free-standing: two powerful model sys- tems for artificial membranes}

Membranes are nature's prime choice for encapsulation and compartmentation of biological molecules and systems. Although there are interesting speculations about the potential role of two-dimensional segregation of molecules on surfaces as the simplest way to establish modular systems (Griffiths, 2007) in early life forms, the large numbers of soluble factors in modern cells require strategies of three-dimensional confinement. Lipids are certainly among the best possible solutions to tightly seal aqueous environments with a maximum of structural flexibility and transformability. Formed entirely by self-organization without chemical energy input, and held together by the exclusion of water from their hydrophobic cores, membranes are remarkably thin structures considering their enormous potential as barriers not only for large molecules, but also for small molecules, and particularly, hydrated ions.

For thorough biophysical characterization of biological membranes with modern biophysical techniques, two model systems have in the past been particularly successful. One is the supported membrane system that consists of a solid support, mostly polished glass or mica surfaces, and a double layer of lipids forming an intact unilamellar membrane on top of it (Tamm and McConnell, 1985; Sackmann, 1996). Due to a thin hydration layer beneath the membrane, it is usually guaranteed that the lipids can move more or less freely and are unaffected by the surface (Yang and Appleyard, 2000). However, as soon as integral membrane proteins are reconstituted into the membrane with hydrophilic residues sticking out more than a few nanometers, pinning can occur, which then requires hydrogel or other polymer cushions to be deposited on the solid support (Tanaka and Sackmann, 2005; Chan and Boxer, 2007), or the use of long polymer tethers (Knoll et al., 2000). The other model system, featuring free-standing membranes with minimal interference with any support, involves giant unilamellar vesicles (GUVs), closed lipid bilayers with diameters well above the optical resolution limit, from several micrometers up to hundreds of micrometers (Akashi et al., 1996). Due to their gigantic sizes, the vesicular membranes can be assumed to be almost flat with vanishing curvature, and are perfectly suited to be investigated by optical microscopy.

In the following, we will briefly discuss these minimal systems for cellular membranes and their specific virtues for biophysical characterization. 


\section{Supported membranes: accessible to many biophysical techniques}

Supported membranes or, as they are frequently called, supported lipid bilayers (SLBs) are usually formed by vesicle fusion, or Langmuir transfer, to the respective surface (Brian and McConnell, 1984). The quality of the bilayer, i.e. the continuity and fluidity of the membrane, depends mainly on the quality of the support. Therefore, intensive cleaning of the glass substrate or using freshly cleaved mica as support is of crucial importance. Once deposited, the membranes are usually quite stable and can be exposed to several preparative and analytical steps. They are even adaptable to surface patterning techniques such as microprinting (Chan and Boxer, 2007; Morigaki et al., 2001).

The biggest advantage of the supported membrane system is its adaptability to a large number of biophysical characterization techniques. Optical microscopy and spectroscopy techniques are easily applicable, but the system is also suitable for scanning probe microscopy, impedance measurements such as quartz crystal microbalance and surface plasmon resonance (Salamon et al., 1994; Janshoff et al., 1997; Keller and Kasemo, 1998; Janshoff and Steinem, 2001) and total internal reflection fluorescence to observe single molecules (Groves et al., 2008; Crane and Tamm, 2007). Consequently, the microand nanostructure of supported membranes with or without integral proteins can be characterized with high precision. If two-dimensional protein crystals, e.g. from the membranes of purple bacteria or from mitochondrial membranes, can be reconstituted, atomic force microscopy (AFM) is even able to resolve atomic details on the external domains of transmembrane proteins (Engel and Müller, 2000).

Apart from the possibility of studying membrane domain formation in symmetric bilayers, as discussed in the next section for free-standing membranes, supported membranes offer the opportunity to create asymmetric bilayers (Kiessling et al., 2006). As most natural membranes are asymmetric with regard to the distribution of lipids in the inner and outer leaflets, this constitutes the possibility of introducing topological motifs mimicking the preferable binding or insertion sites for membrane proteins. Also, the role of domain formation in one leaflet (e.g. by receptor aggregation in life cell membranes) on the lipid distribution in the respective other leaflet can be investigated.

Research on supported membranes has so far been primarily directed towards the elucidation of membrane structure and dynamics (Figure 3) (Saslowsky et al., 2002; Chiantia, et al., 2006; Garcia-Saez et al., 2007), as well as the localization and interaction of membrane proteins (Pautot et al., 2005; Chiantia et al., 2008). As part of the effort to move closer towards physiological situations, protocols have been developed (Perez et al., 2006.) to adhere functional cell membranes to solid supports, by coating coverslips with poly-L-lysine and ripping off parts of upper cell membranes. These native membranes can then be subjected to the same kinds of analytical techniques, including atomic force microscopy, resolving structural features with much higher resolution that would be possible on intact cells.

To circumvent problems induced by large extramembrane domains, another option to generate flat membranes is the use of scaffolds or supports with small enough holes to avoid membrane rupture (Goncalves et al., 2006; Simon et al., 2007). But generally, using vesicles as a means to study free standing membranes, as discussed in the next section, is usually a more straightforward approach.

\section{Free-standing membranes: the giant unilamellar vesicle (GUV) system}

Giant unilamellar vesicles, or GUVs, have in the past 10 years become extremely attractive systems in the study of model membranes, particularly because of their compatibility with optical methods such as light and fluorescence microscopy, and because of the large unperturbed areas of free-standing membranes that they provide. Soon after reliable, easily reproducible protocols for their formation were released (Angelova et al., 1992; Akashi et al., 1996), they were demonstrated to be perfect platforms for the investigation of lipid domain or phase formation in binary or ternary lipid mixtures (Korlach et al., 1999; Bagatolli et al., 2000; Baumgart et al., 2003). They had already earlier been frequently employed in the biophysical investigation of membrane surface transformations under various external and lipidic conditions, following the theoretical models of

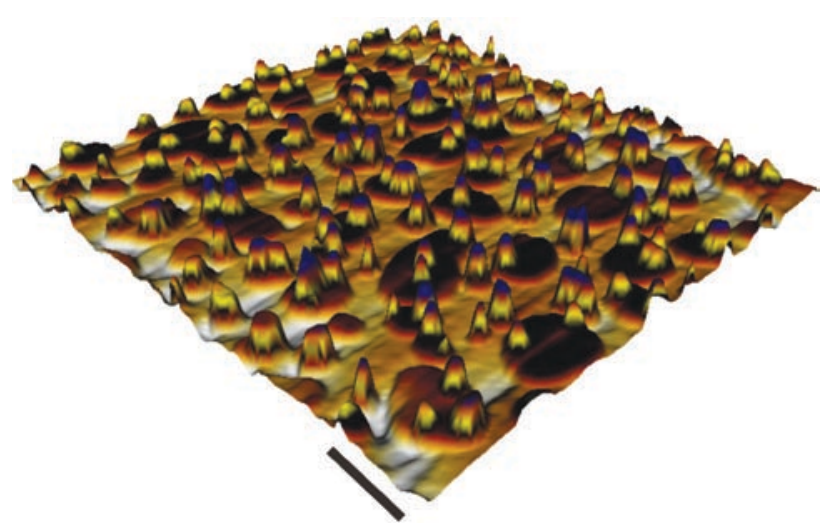

Figure 3. AFM imaging of raft-like domains in a membrane. Here, a supported bilayer composed of SM (sphingomyelin), DOPC cholesterol and ceramide in 0.7:1:0.7:0.3 molar ratio. The three topographical levels correspond to the Ld, Lo and ceramide-rich phases, respectively (see Chiantia et al. 2008). 
fluid crystal mechanics (Helfrich, 1973; Lipowsky, 1991; Lipowsky and Sackmann, 1995; Seifert, 1997).

But the true breakthrough of the GUV model system, making them well-known and widespread tools also among biologists, came shortly after the acknowledgment of the potential biological relevance of detergent resistant membranes (DRMs), or, as they are more popularly called, lipid rafts (Simons and van Meer, 1988; Simons and Ikonen, 1997). The underlying concept is that the heterogeneous lipid distribution in cellular membranes has functional relevance in various biological processes. Under certain conditions, microdomains with different physical properties form within the membrane, and act as platforms for the sorting, enrichment, and activation of membrane-associated proteins. Being enriched in sphingomyelin and cholesterol, these domains proved for a long time impossible to be observed directly in live cells, due to their presumed sub-resolution sizes of less than $100 \mathrm{~nm}$ (Day and Kenworthy, 2009). Although different indirect evidence for local membrane organization and its relevance to protein activity has accumulated (Varma and Mayor, 1998; Rajendran and Simons, 2005;
Wawrezinieck et al., 2005), only the advent of superresolution microscopy seems to provide first direct experimental proof for their - at least transient - existence in live cellular membranes (Eggeling et al., 2009).

Because sphingomyelin and cholesterol are enriched in DRMs and have special hydrogen-bonding properties, they were quickly proposed to be essential ingredients of lipid rafts. This triggered a large number of studies with GUVs composed of what is today called the "canonical raft mixture", i.e. unsaturated PC, sphingomyelin, and cholesterol in about equal amounts (Dietrich et al., 2001; Kahya et al., 2003; Veatch and Keller, 2003a). In GUVs as minimal models for domain-forming membranes (Figure 4A), the co-existence of a liquid-disordered, or fluid, membrane phase, and a more viscous liquidordered phase, could be easily demonstrated by a combination of optical imaging and fluorescence correlation spectroscopy (FCS), using dyes with different partition coefficients in the different membrane environments (Bacia et al., 2004). Spreading vesicles of the same lipid mixture on solid supports such as mica, AFM could at the same time reveal that the liquid-ordered phase,
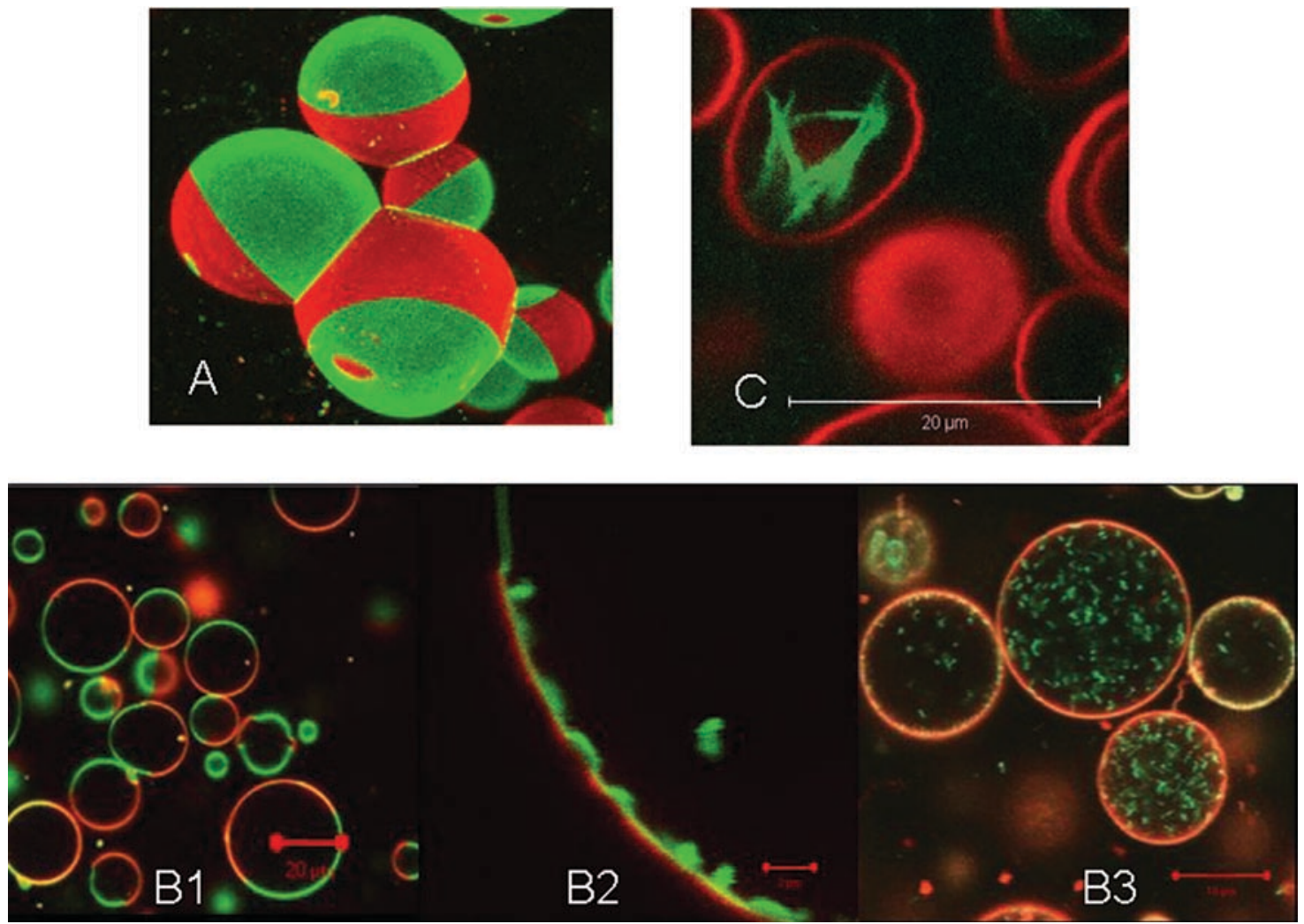

Figure 4. The giant unilamellar vesicle (GUV) model system. A: GUVs made of canonical raft mixture, DOPC, SM, and cholesterol. Red: liquid-disordered phase, Green: liquid-ordered phase. B: Effect of ceramide on membrane structure. GUVs were incubated with SMase from Staphylococcus aureus. B1: before addition of SMase/ceramide, B2: formation of pits and invaginations on the membrane surface, and budding of vesicles, B3: Mother GUV filled with small vesicles formed after Cer addition. Again, GUVs were prepared with a mixture of DOPC, SM, and cholesterol. DiD-C18 (red) and Bodipy-cholesterol (green) were used to label the two lipid phases (Trajkovic et al., 2008). C: Filamentous actin (green), stably anchored to the GUV membrane (red) through the spectrin-ankyrin system (Merkle et al., 2008) 
enriched in sphingomyelin and cholesterol, was about one nanometer thicker than the fluid phase, which corresponds well with the assumption of higher order of the carbohydrate tails in these domains (Saslowsky et al., 2002; Chiantia et al., 2006).

Although much fundamental membrane thermodynamics could be performed with the GUV model system, mapping exact phase diagrams of specific ternary lipid mixtures, including different sterols (Scherfeld et al., 2003; Veatch and Keller, 2003a; Feigenson, 2006; Bacia et al., 2005), one of its most attractive aspects as minimal system naturally involves the functional reconstitution of proteins that are supposed to be raft-associated or involved in raft formation in live cells, and the investigation of their partitioning. Specifically, the aim of these studies with reconstituted proteins in GUV membranes is to elucidate the presumed mutual relationship between the functional state of a protein induced by e.g. aggregation, conformational change, or chemical modification, and its respective lipid environment. It is well conceivable that the functional state determines the partitioning of the protein into either the liquid-ordered or the liquid-disordered state. At the same time, the induction of protein function determines the local membrane order around it. Both effects could be demonstrated in the GUV model system. Hammond et al. (2005) showed that the clustering of GM1 in membranes upon binding of cholera toxin induced domain formation and the resorting of a transmembrane peptide. In a similar assay with more complex membrane vesicles derived from full cell membranes, Lingwood et al. (2008) showed that a considerable fraction of lipid was actually following this re-sorting, being drawn to a more ordered state by the aggregation of protein around it.

The reason that the GUV model system still awaits a large number of proposed in vitro studies to be carried out, e.g. by reconstituting a full signaling system involving receptors and at least parts of a purified transduction machinery, is given by the still limiting procedure of how to reproducibly create giant vesicles at high yield under physiological conditions. So far, the most reliable protocol still involves dehydration and subsequent rehydration of the lipids in the presence of a slowly alternating electrical field, either between two adjacent platinum wires, or sandwiched between two metal-coated coverslips, usually using ITO as the metal substrate. Even if purified proteins withstand the treatment of dehydration and rehydration, the ionic (in particular, salt) conditions of the buffer that allows vesicle electroformation in slowly alternating fields are usually considerably below physiological concentrations. Although recent publications (Pott et al., 2008; Montes et al., 2007) report successful strategies for arriving at higher salt concentrations, these protocols are still not perfectly compatible with complex membrane protein reconstitution.
Nevertheless, a large number of transmembrane proteins have already been successfully transferred in the controlled, even domain-exhibiting, GUV membranes, including bacteriorhodopsin (Kahya et al., 2001), ATPases (Girard et al., 2004) and proteins of the SNARE membrane fusion machinery (Bacia et al., 2004). All of these transmembrane proteins so far have been shown to much prefer the liquid-disordered domains. On the other hand, proteins with membrane anchors such as GPI, or that specifically bind to lipids enriched in rafts (such as cholera toxin and equinatoxin II), could indeed be proven to preferentially segregate into the liquid-ordered domains (Chiantia et al., 2008; Schön et al., 2008).

Another very interesting scenario, however, is to assemble a minimal system of force-inducing or coatforming proteins in vitro, acting on and transforming these artificial membrane systems, with or without domains. This will be discussed in the next sections.

\section{Membrane transformations by cytoplasmic proteins, reconstituted in minimal systems}

Membranes in living cells are by no means stationary entities, but permanently engaged in all kinds of transformation. These involve the uptake and release of molecules, their packaging and transport from and to distinct sites, the transformation of whole organelles and finally, the large-scale restructuring of the cell membrane during cell division. All of these transformations are tightly regulated and catalyzed by specific protein machineries, presumably triggered through a sophisticated interplay between the local lipid environment and the specifically adapted protein structure and function (McMahon and Gallop, 2005). Although force-inducing motor proteins are often involved in large-scale membrane transformations, most of the intracellular membrane traffic, e.g. between the Golgi network and the endoplasmic reticulum, actually relies on the recruitment of cytosolic proteins machineries, called "coats", prone to locally induce buds with large membrane curvature, which can then be easily transformed into transport vesicles. Many of these proteins share as a structural motif amphipathic peptides or helices that can efficiently penetrate the membrane (Farsad and De Camilli, 2003). Best-known coat machineries include the clathrin system (Kirchhausen, 2000), COPI and COPII (Duden, 2003), as well as the lately very prominent BAR domain proteins (McMahon and Gallop, 2005; Antonny, 2006).

In recent years, evidence has accumulated that this recruitment of cytoplasmic coats occurs predominantly at specific sites, e.g. with already existing curvatures through lipid asymmetry, or on domains with higher membrane fluidity. Here, in vitro reconstitution of this machinery onto GUVs or other free-standing membranes 
is a valuable tool to better understand and characterize the physical parameters governing coat protein recruitment and the subsequent membrane transformation in minimal systems (Sens et al., 2008). In such an approach, Manneville etal. (2008) reconstituted the Arf1-dependent assembly of the COPI coat on GUVs by using fluorescently labeled Arf1 and coatomer. They showed that membrane recruitment of Arfl-GTP alone occurs exclusively on disordered lipid domains without inducing membrane deformation. Self-assembly of coatomer, as a next step, induces extensive membrane deformation, but only at low membrane tension, and with different lipid composition from the parental membrane, suggesting that the COPI coat does not only introduce local curvature, but may also promote lipid sorting.

There is rising evidence that in addition to the classical well-characterized systems of cargo uptake such as clathrin and caveolin, several other mechanisms of local protein-lipid interaction can lead to similar effects. If large proteins bind and assemble to one side of a membrane, curvature will result, dependent on the mode of assembly or aggregation. This phenomenon has been recently observed with the Gb3 (glycolipid)-binding B-subunit of bacterial Shiga toxin (Römer et al., 2007). Upon Shiga toxin binding to cell and model membranes, narrow tubular membrane invaginations arose, which were supposed to occur through protein-induced lipid reorganization that favors negative membrane curvature. Interestingly, depending on the mode of assembly or aggregation, membrane deformations can lead to protrusions or invaginations, as shown by Saarikangas et al. (2009) for different BAR proteins.

The relevance of the local lipid environment in membrane deformations and budding was highlighted in another recent study with a focus on intraluminal vesicles of multivesicular endosomes (Trajkovic et al., 2008). In a combined cellular and model membrane study, it was found that cargo is segregated into distinct subdomains on the endosomal membrane, and that the transfer of exosome-associated domains into the lumen of the endosome required the sphingolipid ceramide. Purified exosomes were enriched in ceramide, and the release of exosomes was reduced after the inhibition of neutral sphingomyelinases. On the GUVs, conversion of sphingomyelin into ceramide resulted in the spontaneous, protein-free budding of small vesicles away from the mother membrane (Figure 4B).

Another intriguing recent study on the in vitro reconstitution of the ESCRT-III proteins in GUVs shows membrane bending by the complex in an unconventional way, where bending and budding away from the mother membrane can actually be induced against the direction of coat assembly, i.e. to the inside if the binding occurs from the outside (Barelli and Antonny, 2009; Wollert et al., 2009).

\section{Motor proteins acting on membranes}

Dynamic interactions between the lipid membranes of organelles and the cytoskeleton - most impressively occurring in the form of continuously changing membrane tube networks (Terasaki et al., 1986) - are critical for intracellular trafficking. Performing in vitro experiments using cell-free extracts, it has been shown that motor proteins, moving along cytoskeletal filaments, exert forces on the membranes to which they are attached (Dabora and Sheetz, 1988; Vale and Hotani, 1988). To better understand the formation of membrane tubes by motor proteins, the tube pulling system was first reconstituted by Bassereau and coworkers (Roux et al., 2002) by attaching purified kinesin-1 motors to the membranes of GUVs via micron-sized beads. Later on, the formation of membrane tubes and tubular networks was also observed when kinesin-1 motors were directly linked to the lipids of giant unilamellar vesicles (Koster et al., 2003). The involved forces were measured directly with optical tweezers, and it was hypothesized that the cooperation of multiple motors, but not their rigid linkage to each other, is necessary for tube formation. The existence of an accumulation of motors at the tip of the tubes was confirmed by fluorescence intensity measurements on the motor density along the tubes, and it was determined that the number of motors pulling a tube can range from four to a few tens (Leduc et al., 2004). Remarkably, nonprocessive motors can also cooperatively extract tubes (Shaklee et al., 2008) which exhibit rich dynamics including distinct phases of persistent growth, retraction, and an intermediate bidirectional regime.

A general requirement to couple the activity of cytoskeletal motors to model membranes is the establishment of a proper interface, i.e. the reconstitution of a cytoskeleton- or cortex-like structure on the membrane, through stationary or transient anchors. Actin has been polymerized within GUVs quite early, but without stable attachment between the membrane and the filaments (Limozin and Sackmann, 2002).

One prominent linkage system between the plasma membrane and the actin cytoskeleton is based on the lipid second messenger phosphatidyl-inositol 4,5 bisphosphate $\left(\mathrm{PIP}_{2}\right)$ and the actin nucleation promoting factor neural Wiscott-Aldrich syndrome protein (N-WASP). In a recent approach to anchor an actin network to GUVs, Liu and Fletcher (2006) used this combination of N-WASP, bound to PIP2 and activated Arp2/3 to polymerize actin on the outer surface of GUVs. On phase-separated vesicles, N-WASP, Arp2/3 and actin only formed actin networks on TMR-PIP2 enriched domains. In analyzing the domain melting temperature, they found that the actin network on the surface of the membrane can lead to both: induction of new domains, 
and the stabilization of existing domains. Furthermore, the actin network seems to spatially bias the location of domain formation after cycling the temperature above and below the melting temperature. This system was further reconstituted onto GUVs together with activated ARF1 to verify actin-based propulsion of ARF1 vesicles and establish a minimal system for the dynamics of Golgi membranes (Heuvingh et al., 2007). In another assay, it was found that GUV propulsion is inhibited by the presence of VCA-actin covalent complex, showing that the release of actin from the nucleator is required for movement (Delatour et al., 2008).

A different approach to tightly anchor cytoskeletal elements to GUV membranes was chosen in a recent approach by our group (Merkle et al., 2008) Using porcine total brain lipid extracts rather than synthetic lipids, static linkage of actin filaments through the ankyrin/spectrin machinery bound to functional ion channels in the GUV membrane could be accomplished (Figure 4C).

An interesting mechanism of motor-induced membrane deformation was found in another in vitro approach on GUV systems, employing dynamin (Roux et al., 2006) Dynamin is a GTPase involved in membrane fission in endocytosis. Addition of dynamin and GTP to membrane tubules previously formed from GUVs by the motor activity of kinesin on microtubules resulted in twisting of the tubules and supercoiling, suggesting a rotatory movement of the helix turns relative to each other during GTP hydrolysis. No fission events were however observed in the absence of longitudinal tension.

\section{Part C: Minimal systems for encapsulation of (bio)chemical processes}

Clearly, the most attractive task in synthetic biology is the construction of an artificial cell, or protocell, i.e. a chemical system encapsulated in a closed compartment that is able to self-replicate and evolve (Deamer, 2005; Luisi, 2007). Nucleic acids with their inherent propensity for self-replication are the most favorable candidates for such chemical systems to be encapsulated. Consequently, there are fascinating perspectives of how systems composed entirely of RNA and specific membranes could indeed self-replicate and evolve in the sense that multiple vesicles are generated from a single one, competing for resources (Szostak et al., 2001). However, in these systems, the control over the compartment itself, its size and timing of division, would not or would only indirectly be encoded on and regulated by the encapsulated information. Speaking of membrane vesicles as compartments, it may thus be an even more fascinating perspective to allow the inclusion of proteins to the minimal cell system, and ask for the fundamental protein machinery that could directly couple the replication of nucleic acids to the shape transformations and division of the compartment as such. Introducing proteins to the minimal system naturally enlarges the number of components considerably, although the machinery for in vitro transcription and translation is still of modest size (Shimizu et al., 2001). In a recent review, Forster and Church (2006) arrive at an estimate of $c a .150$ genes, including subsystems for nucleic acid replication, transcription, translation, and a rudimentary system for posttranslational protein modification.

In the following, we will discuss the two most interesting approaches towards an artificial protocell. The first is based on compartmented nucleic acids only; the second integrates purified machineries for cell-free protein translation, and deals with the question of how to best confine these systems together with their respective genetic information, to make the system evolvable. Here, the first straightforward approach was to use water-inoil droplets, although interesting procedures for how to convert these into vesicles could be described.

\section{RNA loaded vesicles as simplest possible protocells}

Probably one of the most elegant approaches for minimal cell systems is based on the "RNA world" hypothesis, i.e. that DNA and proteins are specified classes of molecules, one responsible for information, the other for structure and function, which are both derived from a molecular ancestor: RNA. In this notion, primordial cells, and thus also artificial cell systems, would use RNA both for information encoding and for enzymatic catalysis of its fundamental transitions.

An elegant way of constructing RNA-based protocells was described by Szostak et al. (2001). The molecular preconditions for such a system, ready to self-replicate but also to evolve, were limited to (1) an RNA replicase, to replicate its own sequence; and (2) a membrane compartment tight enough to protect the RNA genotype from the environment, but open for small-molecule substrates such as nucleotides. Moreover, the membrane should allow spontaneous growth, as well as spontaneous division at a critical size, i.e. the division process would be determined in the first place by intrinsic properties of the vesicle and the physical properties of its environment (Hanczyk and Szostak, 2004). Ideally, these two systems of RNA replicase and vesicular membrane would not only be chemically compatible, but also coupled in the way that the RNA ribozyme catalyses the synthesis of amphipathic molecules to directly control the size and growth of its own compartment. In this way a true genotype-phenotype coupling, characteristic of Darwinian evolution, would be guaranteed. 
A few years later, the Szostak group (Chen et al., 2004a) actually succeeded in creating such a coupling, albeit with a much simpler coupling mechanism. They demonstrated that RNA encapsulated in fatty acid vesicles exerts an osmotic pressure on the semipermeable membrane through counter-ions associated with the RNA, whose concentration would rise through RNA replication, and lead to a swelling of the vesicle. This swelling, on the other hand, acts as a driving force for incorporation of more fatty acid molecules to the surface, and consequently couples division to true vesicle growth. It could be shown that osmotically swollen vesicles indeed yielded an "evolutionary" advantage over the isotonic ones, in that they grew on expense of the isotonic vesicles. These experiments demonstrate that the phenomenon of osmotically driven vesicle growth could indeed have played a role in emergence of Darwinian evolution, if first cellular units were built up by similar classes of molecules. In another study (Chen and Szostak, 2004), the same group demonstrated that the growth of fatty acid vesicles also produces a $\mathrm{pH}$ gradient which could be used as an energy source, e.g. to drive the transport of small molecules over the membrane.

Recently, the approach was extended towards the study of activated nucleotide uptake by fatty acid vesicles, combined with a template-copying reaction inside the vesicle where the nucleotides were actually engaged in a non-enzymatic copy of an oligo-dC DNA template (Mansy et al., 2008). In contrast to the fatty acid vesicles, phospholipid vesicles with the same template system did not support a similar copying reaction after addition of activated nucleotides to their exterior, probably indicating that phospholipid membranes only co-evolved together with protein machineries that allowed active transport across them. On the other hand, the easy exchange of nutrients between protocells made of fatty acids suggests that the first simple protocells made of nucleic acids and membranes only have been heterotrophic rather than autotrophic.

\section{Cell free protein expression in droplets}

Although the model system discussed in the last paragraph is extremely attractive in terms of offering the simplest possible solution to a self-replicating entity, and may conceptually be the closest to true primordial cells, it does not give an answer to the at least equally fascinating question, namely: what fundamental functionalities were first delegated to protein molecules? Or, in other words, would there be a rudimentary protein tool-box controlling and improving at least the most important features of protocells, such as replication, growth, and division? Once the environment of first life forms had reached a more or less steady state, the only possible way to generate evolutionary advantages was the generation of better, i.e. more efficient catalysts for the fundamental transitions.

Consequently, other approaches towards artificial cells in the past years have chosen a different strategy, based on proteins and our knowledge about proteins to date. In particular, they use the protein expression machinery of modern cells as a module on its own, to be combined with genes of choice and transplanted into any closed compartment that could resemble the cellular framework. Clearly, these approaches do not claim to be minimal in the sense that the smallest possible number of functional molecules is reached, but they are definitely valuable strategies to dissect the cellular protein machinery and gain information about fundamental relationships between a minimal set of protein components in closed systems. Also, the encapsulation of a protein expression machinery together with a gene of choice represents the basis for Darwinian evolution. The first landmark study elegantly realizing compartmentalization of a cell-free transcription/translation was published by Tawfik and Griffiths (1998), who utilized water-in-oil-emulsions to encapsulate different genes into small water droplets separated by mineral oil, achieving true genotype-phenotype coupling. The technical limitation of this approach, i.e. the heterodispersity of these droplets when generated by simple emulsification, could several years later be overcome, due to the general impact of microfluidics on general fluid handling (Quake and Scherer, 2000). To our knowledge, our own group first published the concept of creating large amounts of homodisperse water-in-oil droplets for cell-free protein expression in soft polymer microstructures (Dittrich et al., 2003), which was later followed up on and technically perfected by other groups (Courtois et al., 2008; Baret et al., 2009). Today, droplet based microfluidics has many exciting applications in chemistry and biology (Link et al., 2006; Clausell-Tormos et al., 2008; Chiu and Lorentz, 2009) with a huge promise for minimal systems design compatible with large number screening (Huebner et al., 2008). Figure 5 shows a chip design for droplet formation, fusion, and storage.

\section{In vitro protein expression in a vesicle}

As discussed above, the droplet approach is a potent tool for evolutionary biotechnology, and appealing also for minimal system design, but has the significant drawback that it is an almost completely closed system, where the exchange between different compartments, or between the compartment and its environment, is basically impossible, due to the mineral oil around the droplets. Thus, the sustainability of these systems is limited by the difficulty of delivering new nutrients and energy after the compartment is once created and closed. In the light of these limitations, a very attractive variation on the theme 


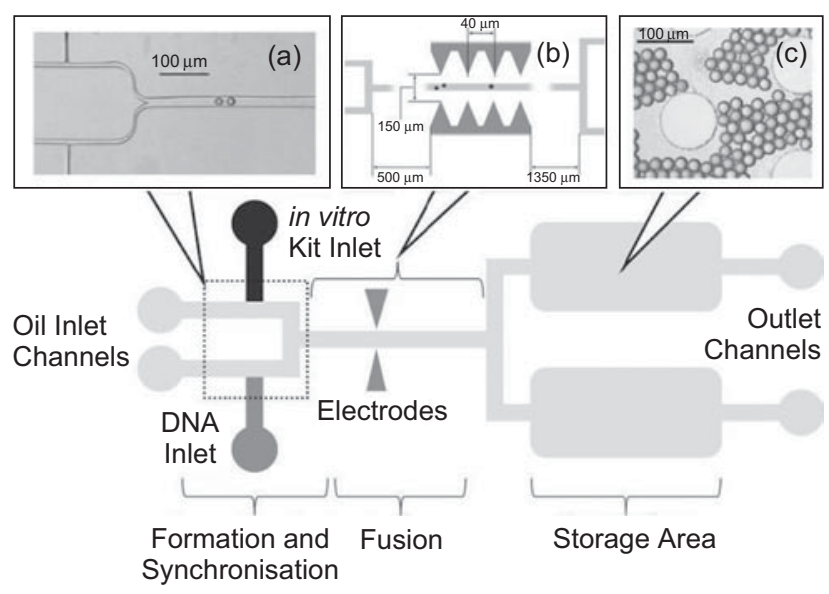

Figure 5. Microfluidic PDMS chip to create microdroplets for cell free protein expression. (a) Water-in-oil droplets are formed in two separate channels, one kind with in vitro expression kit (PURE system or S30 extract), one with DNA, and then synchronized; (b) detailed scheme of the electrode arrangement to fuse droplets; (c) storage area where stabilized droplets can be stored over hours and days.

of compartmented cell-free protein expression was published by the Libchaber group (Noireaux and Libchaber, 2004). In this study, the compartmentation was first achieved in the same way as described above, by emulsification of the extract in mineral oil. Then, however, the water-in-oil system was converted into a water-in-water system by a process of reverse emulsification (Pautot et al., 2003), i.e. by centrifuging the droplets through an oil-water interface and thus creating a fatty acid bilayer from what was first a simple monolayer. The vesicles generated in this way proved to be stable over days, and, what is more, through the incorporation or proteins pores such as alpha-hemolysin, they could also entertain a constant energy supply to the interior, allowing the protein expression machinery to continually function by creating new protein. Over three days, a continuous accumulation of green fluorescent protein was documented.

This proof-of principle of cell-free protein expression in membrane vesicles was particularly exciting, because it constitutes a potent minimal cell system. However, few publications followed up, which is most likely due to the limited efficiency of creating reverse emulsions from droplets with extremely high protein (and ion) content, as dictated by the protein expression machinery mostly generated from cellular extracts. Our group among others tried to reproduce the study in GUVs with very moderate success, mainly due to the low yield of intact vesicles of substantially larger diameters than the optical resolution limit. Better results could be achieved using smaller liposomes (Murtas et al., 2007).

Thus, if the attractive goal of expressing proteins inside vesicles is further pursued, other ways to create and fill these vesicles need to be considered. A very interesting protocol was recently published by the Fletcher group
(Stachowiak et al., 2008). Here again, microsystems technology is being employed, to create a microfluidic jet that forms vesicles through deforming a planar lipid bilayer into a vesicle, filled with solution from the jet. Although this procedure still remains to be tested with different lipid and buffer compositions, it presently appears to be a most attractive and versatile approach to create large numbers of giant vesicles with basically no limitation of inserting complex mixtures or biomolecules.

\section{Part D: Minimal systems for biological pattern formation}

In the final section of this review, we would like to revert to the biophysical goal of reconstituting self-organization in minimal biological systems, and discuss selected advances in achieving pattern formation in space and time. The most attractive systems for physicists are clearly those that show oscillations (Kruse and Jülicher, 2005), for two reasons: first, the theoretical modeling of oscillating systems is most rewarding, with a minimal number of ambiguities, due to the periodic repeat of measurement variables. Second, the occurrence of oscillations has an inherent plausibility for the relevance of a chosen biological model system, and helps to beat criticism of missing physiological relevance, sometimes being a nuisance in the striving for reduced complexity. We will discuss two exciting recent studies of how biological oscillations could be accomplished, one on soluble proteins of the circadian clock, and another one where the oscillatory behavior involves binding to membranes. The latter example is a particularly attractive system through its relevance in bacterial cell division, supposed to establish a pattern that helps the cell to find the middle, i.e. the perfect division site.

\section{Circadian oscillations reconstituted in vitro}

Biochemical oscillations have been studied for a long time, beginning with metabolic oscillations during glycolysis in yeast, evidenced through periodic changes in NADH fluorescence (Pye and Chance, 1966; Higgins, 1967). Periodicity and the existence of pacemaker reactions are among the most important characteristics of living systems, and even in complex organisms some of these oscillations can be observed in spite of the large number of simultaneously present protein interaction networks and circuits. Among the most prominent ones are circadian oscillations to adapt to day/night cycles, DNA synthesis, and cell division. There are several biochemical mechanisms for establishing oscillations; some are based on the regulation of gene expression, others entirely on protein-protein interactions. The most famous example of the former is probably the repressilator 
(Elowitz and Leibler, 2000), which was constructed as a three component negative feedback loop in E. coli, one of the most striking early realizations of synthetic biology. A recent review of general design principles of biochemical oscillators (Novak and Tyson, 2008) gives a very valuable summary of their most important requirements, i.e. the existence of negative feedback, mechanisms for delaying it in time to avoid assumption of a steady state, and a sufficient nonlinearity of the kinetic rate laws of the underlying reactions, in order to destabilize the steady state. In addition, the reactions that produce and consume the chemical species have to occur at appropriate timescale. Since the invention of the repressilator, many transcriptional and non-transcriptional feedback loops were discovered or newly designed in bacterial and mammalian cells (Hasty et al., 2002; Sprinzak and Elowitz, 2005; Stricker et al., 2008; Tigges et al., 2009), however to the best of our knowledge, very few of these have yet been transferred to or even attempted in cell-free minimal systems (Noireaux et al., 2003).

Conversely, for one of the most well-known and attractive biological oscillators - the circadian clock such a transfer to a complete in vitro system has been possible (Nakajima et al., 2005). Specifically, the KaiC phosphorylation cycle from cyanobacteria has been established by simply incubating KaiC with KaiA and $\mathrm{KaiB}$, the other proteins that globally regulate the circadian gene expression. In contrast to other organisms, KaiC prosphorylation is the sole pacemaker for the cyanobacterial circadian system, and not a transcription-translation feedback loop. With their landmark paper, Nakajima et al. demonstrated the robustness of fundamental biological oscillations when reconstituted in minimal systems, showing that the circadian periods in their model system were not only consistent with those measured in vivo, but also stable over a relatively broad range of temperatures, a feature termed "temperature compensation". This again underlines the power of minimal systems approaches to elucidate the fundamental mechanisms of biological pattern formation.

\section{Oscillations and waves formed by Min proteins}

The final experimental demonstration of the power of minimal systems to elucidate biological networks and circuits comes from our own work. It is based on the Min protein system from $E$. Coli, a class of bacterial proteins that seem to play a crucial role in defining the division site, i.e. the positioning of the $\mathrm{Z}$ ring that is thought to induce cytokinesis by constriction. Our motivation to work with this system was first to assemble a minimal machinery to reconstitute protein-driven vesicle division in a potential protocell. This long-term goal will be further discussed at the end of this review. However, there is another reason why this system should be considered a perfect minimal model for biological selforganization: the members of the Min protein family exhibit reproducible and stable pole-to-pole oscillations in vivo, which can be evidenced by video microscopy of GFP-labeled Min proteins in live bacteria (Hu and Lutkenhaus, 1999; Raskin and de Boer, 1999; Hale et al., 2001). Mutants lacking these proteins are prone to divide asymmetrically, giving rise to mini-cells lacking DNA (Adler et al., 1967; de Boer et al., 1989)

The fundamental set of players in cell division consists of three different Min proteins, MinD, MinE, and Min C, where MinD and MinE together are sufficient to induce the oscillations, and MinC mainly acts as a passenger to this dynamic pattern, being the actual inhibitor of $\mathrm{Z}$ ring formation. The current view is that $\mathrm{Z}$ ring formation is directed to the middle of the cell simply through the minimal overall occurrence of MinC right there, whose concentration in average is much higher at the poles through the continuous pole-topole oscillations. The relationship between MinD and MinE can be considered a classical energy consuming self-organized system as suggested by Turing (Turing, 1952). Energy is consumed by MinD, a member of the so-called Walker A cytoskeletal ATPase (WACA) family (de Boer et al., 1991; Löwe and Amos, 2009). The unique feature of MinD among the WACA family is the presence of a membrane targeting sequence (MTS), a 19 amino-acid long amphipathic helix at the C-terminal end of the protein. When bound to ATP, MinD dimerizes and exposes its MTS, which peripherally attaches to the membrane. Importantly, binding of MinD to the membrane shows cooperative behavior arising from protein-protein interaction of the membrane-bound species (Hu and Lutkenhaus 2001; Hu et al., 2002; Suefuji et al., 2002; Lackner et al., 2003). MinE binds to membrane bound MinD, stimulating the ATPase activity of MinD. Subsequently, both proteins detach from the membrane. The dynamic pattern formation is ascribed to dynamical instability driven by the hydrolysis of ATP (Howard et al., 2001; Kruse et al., 2007).

Our approach to modeling these oscillations was to purify the main cellular players of Min oscillations, MinD and MinE, label them fluorescently, and expose them to a supported membrane consisting of the E. coli lipids PE, PG and cardiolipin. Upon addition of ATP, impressive travelling wave patterns on the membrane could be observed (Figure 6), retaining the essential features of cellular oscillations, i.e. MinE following MinD at the trailing edge of the wave, and the relationship between wavelength, propagation speed, and diffusional mobility of the proteins in solution being consistent with the cellular situation (Loose et al. 2008). In FRAP experiments (Fluorescence Recovery After Photobleaching), the photobleached area in the protein band did not move while 

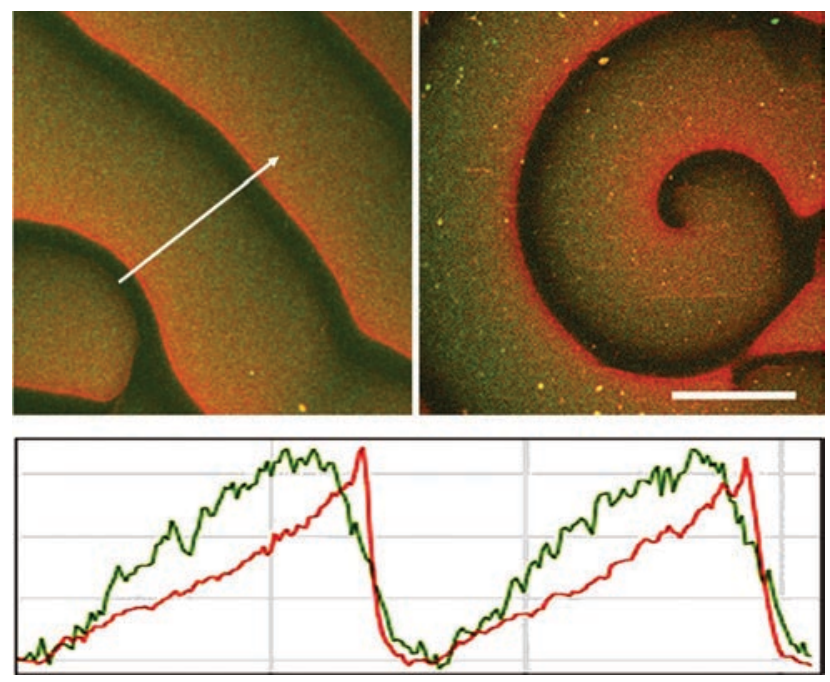

Figure 6. Min oscillations reconstituted in vitro. MinD labeled in green, and MinE labeled in red are added to a supported membrane of $E$. coli lipid mixture and observed by confocal fluorescence microscopy. After addition of ATP, travelling Min waves (along arrow) are formed by protein self-organization within 30-40 minutes. Wavefronts can be parallel (left) or spirals (right) dependent of initial conditions. Lower panel: intensity profiles show that MinE follows MinD at the trailing edge of the wave (Loose et al., 2008).

the wave was propagating, indicating that the waves are the result of repetitive cycles of binding and unbinding events, and not based on directed motion in the plane of the membrane.

Clearly, the next step of minimal system assembly should now be to observe how the Min waves react to the closing of the membrane surface, by injecting the reaction-diffusion system to vesicles. This is the topic of ongoing work in our laboratory. In the future, a co-reconstitution of all Min proteins, MinD, MinE and MinC, with other key molecules of bacterial cell division, such as FtsZ, will be pursued, in order to identify the minimal set of proteins required to divide a vesicle.

\section{Conclusions and outlook}

With this review on fundamental approaches and recent advances of minimal biological system design, we hope to have convinced skeptical readers of the benefits of reductionist biophysical approaches in the elucidation of fundamental biological mechanisms. Especially in the light of increasing knowledge about the actual complexity of biological systems, it is important to master the tools of identifying and properly characterizing the key players. We are aware of the limitations of this approach, due to the "flat hierarchy" in cellular networks that have co-evolved and adapted to each other, thereby accumulating a large number of functional redundancies. Nevertheless, the existence of many conserved proteins and functional features throughout all organisms indicates that there are indeed fundamental mechanisms of life that could be identified, and, hopefully, reduced to a basic set of molecules, such that a quantitative modeling and understanding becomes feasible. We further believe that this approach towards understanding biology is "synthetic biology" in a strict sense, because it intends the construction of biological phenomena de novo, i.e. from key building blocks. Nevertheless, we can and should learn from the established microbial arm of synthetic biology, because their toolboxes, although not completely simplistic, help in reconstituting the most admirable features of existing biological systems, with regard to their potential in solving energy or health problems (Ro et al. 2006).

One way that the biophysical models of synthetic biology, as outlined in this article, can help these aims is the construction of a generally applicable chassis which is not based on or limited to bacterial shells, but could be generalized to vesicular systems. With the help of polymer sciences, these vesicles could later even be constructed of smart polymer materials, giving them better stability and flexibility to function at arbitrary conditions with regard to buffer, temperature, pressure, and otherwise aggressive environments. We thus believe that this interface between classical synthetic biology, biophysics, and materials sciences will be among the most attractive fields in biosciences in the years to come.

\section{Acknowledgments}

We are grateful for the critical reading and input from Salvatore Chiantia, Ana Garcia-Saez, Martin Loose, and Bert Nitzsche, and acknowledge financial support by the Volkswagen foundation for a collaborative project in the funding initiative "Integration of Molecular Components in Functional Macroscopic Systems". PS is presently supported by the Max Planck Society (MPI-CBG Dresden) as a Fellow.

Declaration of interest: The authors report no conflicts of interest. The authors alone are responsible for the content and writing of the paper.

\section{References}

Adler H, Fisher W, Cohen A and Hardigree A. 1967. Miniature Escherichia coli cell deficient in DNA. Proc Natl Acad Sci USA 57:321-326.

Akashi K, Miyata H, Itoh H and Kinosita K. 1996. Preparation of giant liposomes in physiological conditions and their characterization under an optical microscope. Biophys J 71:3242-3250.

Aldaye FA, Palmer AL and Sleiman HF. 2008. Assembling materials with DNA as the guide. Science 321:1795-1799. 
Allen RD, Allen NS and Travis JL. 1981. Video-enhanced contrast, differential interference contrast (Avec-Dic) microscopy - a new method capable of analyzing microtubule-related motility in the reticulopodial network of Allogromia laticollaris. Cell Motil Cytoskeleton 1:291-302.

Allen RD, Metuzals J, Tasaki I, Brady ST and Gilbert SP. 1982. Fast axonal-transport in squid giant-axon. Science 218:1127-1129.

Angelova MI, Soleau S, Meleard P, Faucon JF and Bothorel P. 1992. Preparation of giant vesicles by external AC electric fields. Kinetics and applications. Progr Colloid Polym Sci 89:127-131.

Antonny B. 2006. Membrane deformation by protein coats. Curr Op Cell Biol 18:386-394.

Arkin A. 2008. Setting the standard in synthetic biology. Nat Biotechnol 26: 771-774.

Ashkin A, Schutze K, Dziedzic JM, Euteneuer U and Schliwa M. 1990. Force Generation of Organelle Transport Measured Invivo by An Infrared-Laser Trap. Nature 348:346-348.

Bachand GD, Rivera SB, Carroll-Portillo A, Hess H and Bachand M. 2006. Active capture and transport of virus particles using a biomolecular motor-driven, nanoscale antibody sandwich assay. Small 2:381-385.

Bacia K, Schuette CG, Kahya N, Jahn R and Schwille P. 2004. SNAREs prefer liquid-disordered over "raft" (liquid-ordered) domains when reconstituted into giant unilamellar vesicles. J Biol Chem 279:37951-37955.

Bacia K, Schwille P and Kurzchalia T. 2005. Sterol structure determines the separation of phases and the curvature of the liquidordered phase in model membranes. Proc Natl Acad Sci USA 102:3272-3277.

Badoual M, Julicher F and Prost J. 2002. Bidirectional cooperative motion of molecular motors. Proc Natl Acad Sci USA 99:6696-6701.

Bagatolli LA and Gratton E. 2000. Two photon fluorescence microscopy of coexisting lipid domains in giant unilamellar vesicles of binary phospholipid mixtures. Biophys J 78:290-305.

Barelli $\mathrm{H}$ and Antonny B. 2009. Detached membrane binding. Nature 458:159-160.

Baret J-C, Kleinschmidt F, El Harrak A and Griffiths AD. 2009. Kinetic aspects of emulsion stabilization by surfactants: a microfluidic analysis. Langmuir DOI: 10.1021/la9000472.

Baumgart T, Hess ST and Webb WW. 2003. Imaging coexisting fluid domains in biomembrane models coupling curvature and line tension. Nature 425:821-824.

Bausch AR and Kroy K. 2006. A bottom-up approach to cell mechanics. Nat Phys 2:231-238.

Beeg J, Klumpp S, Dimova R, Gracia RS, Unger E and Lipowsky R. 2008. Transport of beads by several kinesin motors. Biophys J 94:532-541.

Benner SA and Sismour AM. 2005. Synthetic biology. Nat Review Genet 6:533-543.

Bieling P, Laan L, Schek H, Munteanu EL, Sandblad L, Dogterom M, Brunner D and Surrey T. 2007. Reconstitution of a microtubule plusend tracking system in vitro. Nature 450:1100-1105.

Bieling P, Telley IA, Piehler J and Surrey T. 2008. Processive kinesins require loose mechanical coupling for efficient collective motility. Embo Rep 9:1121-1127.

Brian AA and McConnell HM.1984. Allogeneic stimulation of cytotoxic T cells by supported planar membranes. Proc Natl Acad Sci USA 81:6159-6163.

Brouhard GJ, Stear JH, Noetzel TL, Al Bassam, J., Kinoshita K, Harrison SC, Howard J and Hyman AA. 2008. XMAP215 is a processive microtubule polymerase. Cell 132:79-88.

Browne WR and Feringa BL. 2006. Making molecular machines work. Nat Nanotechnol 1:25-35.

Cameron LA, Footer MJ, van Oudenaarden, A and Theriot JA. 1999. Motility of ActA protein-coated microspheres driven by actin polymerization. Proc Natl Acad Sci USA 96:4908-4913.

Canton B, Labno A and Endy D. 2008. Refinement and standardization of synthetic biological parts and devices. Nat Biotechnol 26:787-793.

Chan YHM and Boxer SG. 2007. Model membrane systems and their applications. Curr Op Chem Biol 11:581-587.
Chen IA and Szostak JW. 2004. Membrane growth can generate a transmembrane $\mathrm{pH}$ gradient in fatty acid vesicles. Proc Natl Acad Sci USA 101:7965-7970.

Chen IA, Roberts RW and Szostak JW. 2004. The emergence of competition between model protocells. Science 305:1474-1476.

Chiantia S, Ries J, Kahya N and Schwille P. 2006. Combined AFM and two-focus SFCS study of Raft-exhibiting model membranes. Chem Phys Chem 7:2409-2418.

Chiantia S, Ries J, Chwastek G, Carrer D, Li Z, Bittman R and Schwille P. 2008. Role of ceramide in membrane protein organization investigated by combined AFM and FCS. Biochim Biophys Acta 1778:1356-1364.

Chiu DT and Lorenz RM. 2009. Chemistry and biology in femtoliter and picoliter volume droplets. Accounts of Chemical Research 42(5):649-658.

Choi HJ and Montemagno CD. 2005. Artificial organelle: ATP synthesis from cellular mimetic polymersomes. Nano Lett 5:2538-2542.

Clausell-Tormos J, Lieber D, Baret J, El-Harrak A, Miller O, Frenz L, Blouwolff J, Humphry K, Köster S, Duan H. 2008. Droplet-based microfluidic platforms for the encapsulation and screening of mammalian cells and multicellular organisms. Chem Biol 15:875-875.

Coue M, Lombillo VA and Mcintosh JR. 1991. Microtubule depolymerization promotes particle and chromosome movement in vitro. J Cell Biol 112:1165-1175.

Courtois F, Olguin LF, Whyte G, Bratton D, Huck WTS, Abell C and Hollfelder F. 2008. An integrated device for monitoring time-dependent in vitro expression from single genes in picolitre droplets. ChemBioChem 9:439-446.

Crane JM and Tamm LK. 2007. Fluorescence microscopy to study domains in supported lipid bilayers. Methods Mol Biol 400:481-488.

Crevenna AH, Madathil S, Cohen DN, Wagenbach M, Fahmy K and Howard J. 2008. Secondary structure and compliance of a predicted flexible domain in kinesin-1 necessary for cooperation of motors. Biophys J 95:5216-5227.

Dabora SL and Sheetz MP. 1988. The microtubule-dependent formation of a tubulovesicular network with characteristics of the $\mathrm{Er}$ from cultured-cell extracts. Cell 54:27-35.

Day CA and Kenworthy AK. 2009. Tracking microdomain dynamics in cell membranes. Biochim Biophys Acta Biomembranes 1788:245-253.

Deamer D. 2005. A giant step towards artificial life? Trends Biotechnol 23:336-338.

De Boer PAJ, Crossley RE and Rothfield LI. 1989. A division inhibitor and a topological specificity factor coded for by the minicell locus determine proper placement of the division septum in Escherichia coli. Cell 56:641-649.

De Boer, PAJ, Crossley RE, Hand AR and Rothfield LI. 1991. The mind protein is a membrane ATPase required for the correct placement of the Escherichia coli division site. EMBO J 10:4371-4380.

Delatour V, Helfer E, Didry D, Le KHD, Gaucher JF, Carlier MF and Romet-Lemonne G. 2008. Arp2/3 controls the motile behavior of N-WASP-functionalized GUVs and modulates N-WASP surface distribution by mediating transient links with actin filaments. Biophys J 94:4890-4905.

Diehl MR, Zhang KC, Lee HJ and Tirrell DA. 2006. Engineering cooperativity in biomotor-protein assemblies. Science 311:1468-1471.

Dietrich C, Bagatolli LA, Volovyk ZN, Thompson NL, Levi M, Jacobson K and Gratton E. 2001. Lipid rafts reconstituted in model membranes. Biophys J 80:1417-1428.

Dinu CZ, Opitz J, Pompe W, Howard J, Mertig M and Diez S. 2006. Parallel manipulation of bifunctional DNA molecules on structured surfaces using kinesin-driven microtubules. Small 2:1090-1098.

Dittrich PS and Schwille P. 2003. An integrated microfluidic system for reaction, high-sensitivity detection, and sorting of fluorescent cells and particles. Anal Chem 75:5767-5774.

Dogterom M and Yurke B. 1997. Measurement of the force-velocity relation for growing microtubules. Science 278:856-860. 
Duden R. 2003. ER-to-Golgi transport: COPI and COPII function. Mol Membrane Biol 20:197-207.

Dunn AR and Spudich JA. 2007. Dynamics of the unbound head during myosin V processive translocation. Nat Struct Mol Biol 14:246-248.

Eggeling C, Ringemann C, Sandhoff K, Schönle A, Hell SW et al. 2009. Direct observation of the nanoscale dynamics of membrane lipids in a living cell. Nature 457:1159-1162.

Elowitz MB and Leibler S. 2000. A synthetic oscillatory network of transcriptional regulators. Nature 403(6767):335-338.

Endy D. 2005. Foundations for engineering biology. Nature 438:449-453.

Engel A and Müller DJ. 2002. Observing proteins at work with the atomic force microscope. Nat Struct Biol 7:715-718.

Faivre-Moskalenko C and Dogterom M. 2002. Dynamics of microtubule asters in microfabricated chambers: The role of catastrophes. Proc Natl Acad Sci USA 99:16788-16793.

Farsad K and De Camilli P. 2003. Mechanisms of membrane deformation. Curr Op Cell Biol 15:372-381.

Feigenson GW. 2006. Phase behavior of lipid mixtures. Nat Chem Biol 2:560-563.

Ferber D. 2004. Synthetic biology: Microbes made to order. Science 303:158-161.

Finer JT, Simmons RM and Spudich JA. 1994. Single myosin molecule mechanics - piconewton forces and nanometer steps. Nature 368:113-119.

Fink G, Hajdo L, Skowronek C, Reuther C, Kasprzak AA and Diez S. 2009. The mitotic kinesin-14 drives directional microtubule-microtubule sliding. Nat Cell Biol, Vol. 11(6):717-723.

Footer MJ, Kerssemakers JWJ, Theriot JA and Dogterom M. 2007. Direct measurement of force generation by actin filament polymerization using an optical trap. Proc Natl Acad Sci USA 104:2181-2186

Forster AC and Church GM. 2006. Towards synthesis of a minimal cell. Mol Syst Biol. 2, 45-1 - 45-10.

Funatsu T, Harada Y, Tokunaga M, Saito K and Yanagida T. 1995. Imaging of single fluorescent molecules and individual ATP turnovers by single myosin molecules in aqueous solution. Nature 374:555-559.

Fygenson DK, Marko JF and Libchaber A. 1997. Mechanics of microtubule-based membrane extension. Phys Rev Lett 79:4497-4500.

Garcia-Saez AJ, Chiantia S, Salgado J and Schwille P. 2007. Pore formation by a Bax-derived peptide: effect on the line tension of the membrane probed by AFM. Biophys J 93:103-112.

Gast FU, Dittrich PS, Schwille P, Diez S, Howitz S et al. 2006. The microscopy cell (MicCell), a versatile modular flowthrough system for cell biology, biomaterial research, and nanotechnology. Microfluidics and Nanofluidics 2:21-36.

Girard P, Pecreaux J, Lenoir G, Falson P, Rigaud JL and Bassereau P. 2004. A new method for the reconstitution of membrane proteins into giant unilamellar vesicles. Biophys J 87:2098-2098.

Goel A and Vogel V. 2008. Harnessing biological motors to engineer systems for nanoscale transport and assembly. Nat Nanotechnol 3:465-475.

Goncalves RP, Agnus G, Sens P, Houssin C, Bartenlian B and Scheuring S. 2006. Two-chamber AFM: probing membrane proteins separating two aqueous compartments. Nat Meth 3:1007-1012.

Griffiths G 2007. Cell evolution and the problem of membrane topology. Nat Rev Mol Cell Biol 8:1018-1024.

Gross SP, Tuma MC, Deacon SW, Serpinskaya AS, Reilein AR and Gelfand VI. 2002. Interactions and regulation of molecular motors in Xenopus melanophores. J Cell Biol 156:855-865.

Groves JT, Parthasarathy R and Forstner MB. 2008. Fluorescence imaging of membrane dynamics. Annu Rev Biomed Eng 10:311-338.

Ha T, Enderle T, Ogletree DF, Chemla DS, Selvin PR and Weiss S. 1996. Probing the interaction between two single molecules: Fluorescence resonance energy transfer between a single donor and a single acceptor. Proc Natl Acad Sci USA 93:6264-6268.

Hale CA, Meinhardt H and de Boer PAJ. 2001. Dynamic localization cycle of the cell division regulator MinE in Escherichia coli. EMBO J 20:1563-1572.

Hammond AT, Heberle FA, Baumgart T, Holowka D, Baird B and Feigenson GW. 2005. Crosslinking a lipid raft component triggers liquid ordered-liquid disordered phase separation in model plasma membranes. Proc Natl Acad Sci USA 102:6320-6325.

Hanczyc MM and Szostak JW. 2004. Replicating vesicles as models of primitive cell growth and division. Curr Op Chem Biol 8:660-664.

Hartwell LH, Hopfield JJ, Leibler S and Murray AW. 1999. From molecular to modular cell biology. Nature 402:C47-C52.

Hasty J, McMillen D and Collins JJ. 2002. Engineered gene circuits. Nature 420:224-230.

Hawking SW. 2001. The Universe in a Nutshell. New York, NY: Bantam Books.

Heald R, Tournebize R, Blank T, Sandaltzopoulos R, Becker P, Hyman A and Karsenti E. 1996. Self-organization of microtubules into bipolar spindles around artificial chromosomes in Xenopus egg extracts. Nature 382:420-425.

Helenius J, Brouhard G, Kalaidzidis Y, Diez S and Howard J. 2006. The depolymerizing kinesin MCAK uses lattice diffusion to rapidly target microtubule ends. Nature 441:115-119.

Helfrich W. 1973. Elastic properties of lipid bilayers - theory and possible experiments. Z Naturforsch C 28:693-703.

Hess H. 2006. Self-assembly driven by molecular motors. Soft Matter 2:669-677.

Hess H and Vogel V. 2001. Molecular shuttles based on motor proteins: Active transport in synthetic environments. Rev Mol Biotechnol 82:67-85.

Hess H, Clemmens J, Qin D, Howard J and Vogel V. 2001. Lightcontrolled molecular shuttles made from motor proteins carrying cargo on engineered surfaces. Nano Lett 1:235-239.

Hess H, Howard J and Vogel V. 2002. A piconewton forcemeter assembled from microtubules and kinesins. Nano Lett 2:1113-1115.

Heuvingh J, Franco M, Chavrier P and Sykes C. 2007. ARF1-mediated actin polymerization produces movement of artificial vesicles. Proc Natl Acad Sci USA 104:16928-16933.

Higgins J. 1967. Theory of oscillating reactions. Ind Eng Chem 59:18-\&.

Hiratsuka Y, Tada T, Oiwa K, Kanayama T and Uyeda TQP. 2001. Controlling the direction of kinesin-driven microtubule movements along microlithographic tracks. Biophys J 81:1555-1561.

Holy TE, Dogterom M, Yurke B and Leibler S. 1997. Assembly and positioning of microtubule asters in microfabricated chambers. Proc Natl Acad Sci USA 94:6228-6231.

Howard J. 2001. Mechanics of Motor Proteins and the cytoskeleton. Sunderland, MA: Sinauer Associates.

Howard J, Hudspeth AJ and Vale RD. 1989. Movement of microtubules by single kinesin molecules. Nature 342:154-158.

Howard M, Rutenberg AD and de Vet S. 2001. Dynamic compartmentalization of bacteria: Accurate division in E-coli. Phys Rev Lett 87:278102.

$\mathrm{Hu} \mathrm{Z}$ and J. Lutkenhaus (1999) Topological regulation of cell division in Escherichia coli involves rapid pole to pole oscillation of the division inhibitor MinC under the control of MinD and MinE. Mol Microbiol. 34:82-90.

Hu ZL, Gogol EP and Lutkenhaus J. 2002. Dynamic assembly of MinD on phospholipid vesicles regulated by ATP and MinE. Proc Natl Acad Sci USA 99:6761-6766.

Huebner A, Sharma S, Srisa-Art M, Hollfelder F, Edel JB and Demello AJ. 2008. Microdroplets: A sea of applications? Lab Chip 8:1244-1254.

Inoue S. 1981. Video image-processing greatly enhances contrast, quality, and speed in polarization-based microscopy. J Cell Biol 89:346-356.

Ionov L, Stamm M and Diez S. 2005. Size sorting of protein assemblies using polymeric gradient surfaces. Nano Lett 5:1910-1914.

Ionov L, Stamm M and Diez S. 2006. Reversible switching of microtubule motility using thermoresponsive polymer surfaces. Nano Lett 6:1982-1987.

Janshoff A and Steinem C. 2001. Scanning force microscopy of artificial membranes. ChemBioChem 2:799-808.

Janshoff A, Steinem C, Sieber M, el Baya A, Schmidt MA and Galla HJ. 1997. Quartz crystal microbalance investigation of the interaction of bacterial toxins with ganglioside containing solid supported membranes. Eur Biophys J Biophys Lett 26:261-270. 
Kahya N, Pecheur EI, de Boeij WP, Wiersma DA and Hoekstra D. 2001. Reconstitution of membrane proteins into giant unilamellar vesicles via peptide-induced fusion. Biophys J 81:1464-1474.

Kahya N, Scherfeld D, Bacia K, Poolman B and Schwille P. 2003. Probing lipid mobility of raft-exhibiting model membranes by fluorescence correlation spectroscopy. J Biol Chem 278:28109-28115.

Kapitein LC, Peterman EJG, Kwok BH, Kim JH, Kapoor TM and Schmidt CF. 2005. The bipolar mitotic kinesin Eg5 moves on both microtubules that it crosslinks. Nature 435:114-118.

Kapitein LC, Kwok BH, Weinger JS, Schmidt CF, Kapoor TM and Peterman EJP. 2008. Microtubule cross-linking triggers the directional motility of kinesin-5. Journal of Cell Biology. 182(3): 421-428.

Keller CA and Kasemo B. 1998. Surface specific kinetics of lipid vesicle adsorption measured with a quartz crystal microbalance. Biophys J 75:1397-1402.

Kiessling V., Crane, J.M., Tamm L.K. (2006). Transbilayer Effects of Raft-Like Lipid Domains in Asymmetric Planar Bilayer Measured by Single Molecule Tracking Biophysical Journal. 91: 3313-3326.

Kinoshita K, Arnal I, Desai A, Drechsel DN and Hyman AA. 2001. Reconstitution of physiological microtubule dynamics using purified components. Science 294:1340-1343.

Kirchhausen T. 2000. Clathrin. Annu Rev Biochem 69:699-727.

Knoll W etal. 2000. Functional tethered lipid bilayers. Rev Mol Biotechnol 74:137-158.

Korlach J, Schwille P, Webb WW and Feigenson GW. 1999. Characterization of lipid bilayer phases by confocal microscopy and fluorescence correlation spectroscopy Proc Natl Acad Sci USA 96:9966-9966.

Koster G, VanDuijn M, Hofs B and Dogterom M. 2003. Membrane tube formation from giant vesicles by dynamic association of motor proteins. Proc Natl Acad Sci USA 100:15583-15588.

Kron SJ and Spudich JA. 1986. Fluorescent actin-filaments move on myosin fixed to a glass-surface. Proc Natl Acad Sci USA 83:6272-6276.

Kruse K and Jülicher F. 2005. Oscillations in Cell Biology. Curr Opin Cell Biol 17:20-26.

Kruse K, Howard M and Margolin W. 2007. An experimentalist's guide to computational modelling of the Min system. Mol Microbiol 63:1279-1284.

Lackner LL, Raskin DM and de Boer PAJ. 2003. ATP-dependent interactions between Escherichia coli Min proteins and the phospholipid membrane in vitro. J Bacteriol 185:735-749.

Lasek RJ and Brady ST. 1985. Attachment of transported vesicles to microtubules in axoplasm is facilitated by Amp-Pnp. Nature 316:645-647.

Leduc C, Campas O, Zeldovich KB, Roux A, Jolimaitre P, BourelBonnet L, Goud B, Joanny JF, Bassereau P and Prost J. 2004. Cooperative extraction of membrane nanotubes by molecular motors. Proc Natl Acad Sci USA 101:17096-17101.

Leduc C, Ruhnow F, Howard J and Diez S. 2007. Detection of fractional steps in cargo movement by the collective operation of kinesin-1 motors. Proc Natl Acad Sci USA 104:10847-10852.

Limberis L and Stewart RJ. 2000. Toward kinesin-powered microdevices. Nanotechnol 11:47-51.

Limozin L and Sackmann E. 2002. Polymorphism of cross-linked actin networks in giant vesicles. Phys Rev Lett 89: 168103-1168103-4

Lin CT, Kao MT, Kurabayashi K and Meyhofer E. 2008. Self-contained biomolecular motor-driven protein sorting and concentrating in an ultrasensitive microfluidic chip. Nano Lett 8:1041-1046.

Lingwood D, Ries J, Schwille P and Simons K. 2008. Plasma membranes are poised for activation of raft phase coalescence at physiological temperature. Proc Natl Acad Sci USA 105:10005-10010.

Link DR, Grasland-Mongrain E, Duri A, Sarrazin F, Cheng ZD, Cristobal G, Marquez M and Weitz DA. 2006. Electric control of droplets in microfluidic devices. Angew Chem Int Ed 45:2556-2560.

Lipowsky R. 1991. The conformation of membranes. Nature 349:475-481.
Lipowsky R and Sackmann E. 1995. Structure and Dynamics of Membranes. North Holland: Elsevier.

Liu AP and Fletcher DA. 2006. Actin polymerization serves as a membrane domain switch in model lipid bilayers. Biophys. J. 91:4064-70.

Loisel TP, Boujemaa R, Pantaloni D and Carlier MF. 1999. Reconstitution of actin-based motility of Listeria and Shigella using pure proteins. Nature 401:613-616.

Loose M, Fischer-Friedrich E, Ries J, Kruse K and Schwille P. 2008. Spatial regulators for bacterial cell division self-organize into surface waves in vitro. Science 320:789-792.

Löwe J and Amos LA. 2009. Evolution of cytomotive filaments: The cytoskeleton from prokaryotes to eukaryotes. Int J Biochem Cell Biol 41:323-329.

Luisi PL. 2007. Chemical aspects of synthetic biology. Chem Biodivers 4:603-621.

Manneville JB, Casella JF, Ambroggio E, Gounon P, Bertherat J, Bassereau P, Cartaud J, Antonny B and Goud B. 2008. COPI coat assembly occurs on liquid-disordered domains and the associated membrane deformations are limited by membrane tension. Proc Natl Acad Sci USA 105:16946-16951.

Mansson A, Balaz M, Albet-Torres N and Rosengren KJ. 2008. In vitro assays of molecular motors - impact of motor-surface interactions. Frontiers Biosci 13:5732-5754.

Mansy SS, Schrum JP, Krishnamurthy M, Tobe S, Treco DA and Szostak JW. 2008. Template-directed synthesis of a genetic polymer in a model protocell. Nature 454:122-U10.

Marcy Y, Prost J, Carlier MF and Sykes C. 2004. Forces generated during actin-based propulsion: A direct measurement by micromanipulation. Proc Natl Acad Sci USA 101:5992-5997.

McMahon HT and Gallop JL. 2005. Membrane curvature and mechanisms of dynamic cell membrane remodelling. Nature 438:590-596.

Merkle D, Kahya N and Schwille P. 2008. Reconstitution and anchoring of cytoskeleton inside giant unilamellar vesicles. ChemBioChem 9:2673-2681.

Mitchison T and Kirschner M. 1984. Dynamic instability of microtubule growth. Nature 312:237-242.

Montes LR, Alonso A, Goñi FM, Bagatolli LA. 2007. Giant Unilamellar Vesicles Electroformed from Native Membranes and Organic Lipid Mixtures under Physiological Conditions. Biophys J. 93(10): 3548-3554.

Mori T, Vale RD and Tomishige M. 2007. How kinesin waits between steps. Nature 450:750-U15.

Morigaki K, Baumgart T, Offenhausser A and Knoll W. 2001. Patterning solid-supported lipid bilayer membranes by lithographic polymerization of a diacetylene lipid. Angew Chem Int Ed 40:172-174.

Murtas G, Kuruma Y, Bianchini P, Diaspro A and Luisi PL. 2007. Protein synthesis in liposomes with a minimal set of enzymes. Biochem Biophys Res Comm 363:12-17.

Nagashima H and Asakura S 1980. Dark-field light microscopic study of the flexibility of f-actin complexes. J Mol Biol 136:169-182.

Nakajima M, Imai K, Ito H, Nishiwaki T, Murayama Y, Iwasaki H, Oyarna T and Kondo T. 2005. Reconstitution of circadian oscillation of cyanobacterial KaiC phosphorylation in vitro. Science 308:414-415.

Nedelec FJ, Surrey T, Maggs AC and Leibler S. 1997. Self-organization of microtubules and motors. Nature 389:305-308.

Noireaux V and Libchaber A. 2004. A vesicle bioreactor as a step toward an artificial cell assembly. Proc Natl Acad Sci USA 101:17669-17674.

Noireaux V, Bar-Ziv R and Libchaber A. 2003. Principles of cell-free genetic circuit assembly. Proc Natl Acad Sci USA 100:12672-12677.

Novák B and Tyson JJ. 2008. Design principles of biochemical oscillators. Nat Rev Mol Cell Biol 9:981-991.

Paschal BM, Shpetner HS and Vallee RB. 1991. Purification of brain cytoplasmic dynein and characterization of its in vitro properties. Meth Enzymol 196:181-191.

Pautot S, Frisken BJ and Weitz DA. 2003. Engineering asymmetric vesicles. Proc Natl Acad Sci USA 100:10718-10721. 
Pautot S, Lee H, Isacoff EY and Groves JT. 2005. Neuronal synapse interaction reconstituted between live cells and supported lipid bilayers. Nat Chem Biol 1:283-289.

Perez JB, Martinez KL, Segura JM and Vogel H. 2006. Supported cellmembrane sheets for functional fluorescence imaging of membrane proteins. Adv Funct Mat 16:306-312.

Pierce DW, HomBooher N and Vale RD. 1997. Imaging individual green fluorescent proteins. Nature 388:338-338.

Pott T, Bouvrais $\mathrm{H}$ and Meleard P. 2008. Giant unilamellar vesicle formation under physiologically relevant conditions. Chem Phys Lipids 154:115-119.

Pye Kand Chance B. 1966. Sustained sinusoidal oscillations of reduced pyridine nucleotide in a cell-free extract of Saccharomyces carlsbergensis. Proc Natl Acad Sci USA 55:888.

Quake SR and Scherer A. 2000. From micro- to nanofabrication with soft materials. Science 290:1536-1540.

Raab M and Hancock WO. 2008. Transport and detection of unlabeled nucleotide targets by microtubules functionalized with molecular beacons. Biotechnol Bioeng 99:764-773.

Rajendran L and Simons K. 2005. Lipid rafts and membrane dynamics. J Cell Sci 118:1099-1102.

Raskin DM and de Boer PA. 1999. Rapid pole-to-pole oscillation of a protein required for directing division to the middle of Escherichia coli. Proc Natl Acad Sci USA. 96:4971-4976.

Reck-Peterson SL, Yildiz A, Carter AP, Gennerich A, Zhang N and Vale RD. 2006. Single molecule analysis of dynein processivity and stepping behavior. Cell 126: 335-348.

Reuther C, Hajdo L, Tucker R, Kasprzak AA and Diez S. 2006. Biotemplated nanopatterning of planar surfaces with molecular motors. Nano Lett 6:2177-2183.

Ro DK, Paradise EM, Ouellet M, Fisher KJ, Keasling JD et al. 2006. Production of the antimalarial drug precursor artemisinic acid in engineered yeast. Nature 440: 940-943.

Römer W, Berland L, Sens P, Bassereau P, Johannes L, et al. 2007. Shiga toxin induces tubular membrane invaginations for its uptake into cells. Nature 450(7170):670.

Rothemund PWK. 2006. Folding DNA to create nanoscale shapes and patterns. Nature 440:297-302.

Roux A, Cappello G, Cartaud J, Prost J, Goud B and Bassereau P. 2002. A minimal system allowing tubulation with molecular motors pulling on giant liposomes. Proc Natl Acad Sci USA 99:5394-5399.

Roux A, Uyhazi K, Frost A and De Camilli P. 2006. GTP-dependent twisting of dynamin implicates constriction and tension in membrane fission. Nature 441(7092):528-531.

Saarikangas J, Zhao HX, Pykalainen A, Laurinmaki P, Mattila PK, Kinnunen PKJ, Butcher SJ and Lappalainen P. 2009. Molecular mechanisms of membrane deformation by I-BAR domain proteins. Curr Biol 19:95-107.

Sackmann E. 1996. Supported membranes: Scientific and practical applications. Science 271:43-48.

Salamon Z, Wang Y, Tollin G and Macleod HA. 1994. Assembly and molecular-organization of self-assembled lipid bilayers on solid substrates monitored by surface-plasmon resonance spectroscopy. Biochim Biophys Acta Biomembranes 1195:267-275.

Saslowsky DE, Lawrence J, Ren XY, Brown DA, Henderson RM and Edwardson JM. 2002. Placental alkaline phosphatase is efficiently targeted to rafts in supported lipid bilayers. J Biol Chem 277:26966-26970.

Scherfeld D, Kahya N and Schwille P. 2003. Lipid dynamics and domain formation in model membranes composed of ternary mixtures of unsaturated and saturated phosphatidylcholines and cholesterol. Biophys J 85:3758-3768.

Schnapp BJ, Vale RD, Sheetz MP and Reese TS. 1985. Single microtubules from squid axoplasm support bidirectional movement of organelles. Cell 40:455-462.

Schön P, Garcia-Saez AJ, Malovrh P, Bacia K, Anderluh G and Schwille $P$ 2008. Equinatoxin II permeabilizing activity depends on the presence of sphingomyelin and lipid phase coexistence. Biophys J 95:691-698.

Seeman NC and Belcher AM. 2002. Emulating biology: Building nanostructures from the bottom up. Proc Natl Acad Sci USA 99:6451-6455.
Seifert U. 1997. Configurations of fluid membranes and vesicles. Adv Phys 46:13-137.

Sens P, Johannes L and Bassereau P. 2008. Biophysical approaches to protein-induced membrane deformations in trafficking. Curr Op Cell Biol 20:476-482.

Shaklee PM, Idema T, Koster G, Storm C, Schmidt T and Dogterom M. 2008. Bidirectional membrane tube dynamics driven by nonprocessive motors. Proc Natl Acad Sci USA 105:7993-7997.

Shimizu Y, Inoue A, Tomari Y, Suzuki T, Yokogawa T, Nishikawa K and Ueda T. 2001. Cell-free translation reconstituted with purified components. Nature Biotechnol 19:751-755.

Simon A, Girard-Egrot A, Sauter F, Pudda C, Picollet D, Hahan N, Blum L, Chatelain F and Fuchs A. 2007. Formation and stability of a suspended biomimetic lipid bilayer on silicon submicrometer-sized pores J Coll Interf Sci 308: 337-343.

Simons K and Ikonen E. 1997. Functional rafts in cell membranes. Nature 387:569-572.

Simons K and van Meer G. 1988. Lipid sorting in epithelial cells. Biochemistry 27:6197-6202.

Sprinzak D and Elowitz MB. 2005. Reconstruction of genetic circuits. Nature 438:443-448.

Stachowiak JC, Richmond DL, Li TH, Liu AP, Parekh SH and Fletcher DA. 2008. Unilamellar vesicle formation and encapsulation by microfluidic jetting. Proc Natl Acad Sci USA 105:4697-4702.

Stricker J, Cookson S, Bennett MR, Mather WH, Tsimring LH and Hasty J. 2008. A fast, robust and tunable synthetic gene oscillator Nature 456:516-519.

Suefuji K, Valluzz R and RayChaudhuri D. 2002. Dynamic assembly of MinD into filament bundles modulated by ATP, phospholipids, and MinE. Proc Natl Acad Sci USA 99:16776-16781.

Svoboda K and Block SM. 1994. Force and velocity measured for single kinesin molecules. Cell 77:773-784.

Svoboda K, Schmidt CF, Schnapp BJ and Block SM. 1993. Direct observation of kinesin stepping by optical trapping interferometry. Nature 365:721-727.

Szostak JW, Bartel DP and Luisi PL. 2001. Synthesizing life. Nature 409:387-390.

Tamm LK and McConnell HM. 1985. Supported phospholipid bilayers. Biophys J 47:105-113.

Tanaka M and Sackmann E. 2005. Polymer-supported membranes as models of the cell surface. Nature 437:656-663.

Tao L, Mogilner A, Civelekogiu-Scholey G, Wollman R, Evans J, Stahlberg H and Scholey JM. 2006. A homotetrameric kinesin-5, KLP61F, bundles microtubles and antagonizes Ncd in motility assays. Curr Biol 16:2293-2302.

Tawfik DS and Griffiths AD. 1998. Man-made cell-like compartments for molecular evolution. Nat Biotechnol 16:652-656.

Terasaki M, Chen LB and Fujiwara K. 1986. Microtubules and the endoplasmic-reticulum are highly interdependent structures. J Cell Biol 103:1557-1568.

Theriot JA, Mitchison TJ, Tilney LG and Portnoy DA. 1992. The rate of actin-based motility of intracellular Listeriamonocytogenes equals the rate of actin polymerization. Nature 357:257-260.

Thompson RE, Larson DR and Webb WW. 2002. Precise nanometer localization analysis for individual fluorescent probes. Biophys J 82:2775-2783.

Tigges M, Marquez-Lago TT, Stelling J and Fussenegger M. 2009. A tunable synthetic mammalian oscillator. Nature 457:309-312.

Trajkovic K, Hsu C, Chiantia S, Rajendran L, Wenzel D, Wieland F, Schwille P, Brügger B and Simons M. 2008. Ceramide triggers budding of exosome vesicles into multivesicular Endosomes. Science 319(5867):1244-1247.

Tran PT, Marsh L, Doye V, Inoue S and Chang F. 2001. A mechanism for nuclear positioning in fission yeast based on microtubule pushing. J Cell Biol 153:397-411.

Turing AM. 1952. The chemical basis of morphogenesis. Phil Trans Roy Soc Lond B Biol Sci 237:37-72.

Urrutia R, McNiven MA, Albanesi JP, Murphy DB and Kachar B. 1991. purified kinesin promotes vesicle motility and induces active sliding between microtubules in vitro. Proc Natl Acad Sci USA 88:6701-6705 
Vale RD and Hotani H. 1988. Formation of membrane networks in vitro by kinesin-driven microtubule movement. J Cell Biol 107:2233-2241.

Vale RD, Reese TS and Sheetz MP. 1985a. Identification of a novel force-generating protein, kinesin, involved in microtubulebased motility. Cell 42:39-50.

Vale RD, Schnapp BJ, Reese TS and Sheetz MP. 1985b. Organelle, bead, and microtubule translocations promoted by soluble factors from the squid giant-axon. Cell 40:559-569.

Vale RD, Malik F and Brown D. 1992. Directional instability of microtubule transport in the presence of kinesin and dynein, 2 opposite polarity motor proteins. J Cell Biol 119:1589-1596.

Vale RD, Funatsu T, Pierce DW, Romberg L, Harada Y and Yanagida T. 1996. Direct observation of single kinesin molecules moving along microtubules. Nature 380:451-453.

van den Heuvel MGL and Dekker C. 2007. Motor proteins at work for nanotechnology. Science 317:333-336.

van den Heuvel MGL, Butcher CT, Smeets RMM, Diez S and Dekker C. 2005. High rectifying efficiencies of microtubule motility on kinesin-coated gold nanostructures. Nano Lett 5:1117-1122.

van den Heuvel MGL, De Graaff MP and Dekker C. 2006. Molecular sorting by electrical steering of microtubules in kinesin-coated channels. Science 312:910-914.

Varga V, Helenius J, Tanaka K, Hyman AA, Tanaka TU and Howard J. 2006. Yeast kinesin-8 depolymerizes microtubules in a lengthdependent manner, Nat Cell Biol 8:957-962.
Varma R and Mayor S. 1998. GPI-anchored proteins are organized in submicron domains at the cell surface. Nature 394:798-801.

Veatch SL and Keller SL. 2003a. A closer look at the canonical 'raft mixture' in model membrane studies. Biophys J 84:725-726.

Veatch SL and Keller SL. 2003b. Separation of liquid phases in giant vesicles of ternary mixtures of phospholipids and cholesterol. Biophys J 85:3074-3083.

Wawrezinieck L, Rigneault H, Marguet D and Lenne PF. 2005. Fluorescence correlation spectroscopy diffusion laws to probe the submicron cell membrane organization. Biophys J 89:4029-4042.

Weisenberg RC. 1972 Science,177(4054):1104 - 1105.

Winfree E, Liu FR, Wenzler LA and Seeman NC. 1998. Design and self-assembly of two-dimensional DNA crystals. Nature 394:539-544.

Wollert T, Wunder C, Lippincott-Schwartz J and Hurley JH. 2009. Membrane scission by the ESCRT-III complex. Nature 458:172-1U2.

Yanagida T, Nakase M, Nishiyama K and Oosawa F. 1984. Direct observation of motion of single $\mathrm{f}$-actin filaments in the presence of myosin. Nature 307:58-60.

Yang J and Appleyard J. 2000. The main phase transition of micasupported phosphatidylcholine membranes. J Phys Chem B 104:8097-8100.

Yildiz A, Forkey JN, McKinney SA, Ha T, Goldman YE and Selvin PR. 2003. Myosin V walks hand-over-hand: Single fluorophore imaging with 1.5-nm localization. Science 300:2061-2065.

Editor: Michael M. Cox 